\title{
REVIEW
}

Open Access

\section{Development of a consensus statement on the role of the family in the physical activity, sedentary, and sleep behaviours of children and youth}

Ryan E. Rhodes ${ }^{1}$, Michelle D. Guerrero², Leigh M. Vanderloo ${ }^{3}$, Kheana Barbeau ${ }^{2,4}$, Catherine S. Birken ${ }^{5}$, Jean-Philippe Chaput ${ }^{2}$, Guy Faulkner ${ }^{6}$, Ian Janssen', Sheri Madigan ${ }^{8}$, Louise C. Mâsse ${ }^{9}$, Tara-Leigh McHugh ${ }^{10}$, Megan Perdew ${ }^{1}$, Kelly Stone ${ }^{11}$, Jacob Shelley ${ }^{12}$, Nora Spinks ${ }^{13}$, Katherine A. Tamminen ${ }^{14}$, Jennifer R. Tomasone ${ }^{7}$, Helen Ward ${ }^{15}$, Frank Welsh ${ }^{16}$ and Mark S. Tremblay ${ }^{2 *}$

\footnotetext{
Abstract

Background: Children and youth who meet the physical activity, sedentary, and sleep behaviour recommendations in the Canadian 24-Hour Movement Guidelines are more likely to have desirable physical and psychosocial health outcomes. Yet, few children and youth actually meet the recommendations. The family is a key source of influence that can affect lifestyle behaviours. The purpose of this paper is to describe the process used to develop the Consensus Statement on the Role of the Family in the Physical Activity, Sedentary, and Sleep Behaviours of Children and Youth (0-17 years) and present, explain, substantiate, and discuss the final Consensus Statement.

Methods: The development of the Consensus Statement included the establishment of a multidisciplinary Expert Panel, completion of six reviews (three literature, two scoping, one systematic review of reviews), custom data analyses of Statistics Canada's Canadian Health Measures Survey, integration of related research identified by Expert Panel members, a stakeholder consultation, establishment of consensus, and the development of a media, public relations, communications and launch plan.

\footnotetext{
* Correspondence: mtremblay@cheo.on.ca

${ }^{2}$ Healthy Active Living and Obesity Research Group, Children's Hospital of Eastern Ontario Research Institute, 401 Smyth Road, Ottawa, ON K1H 8L1, Canada

Full list of author information is available at the end of the article
}

(C) The Author(s). 2020 Open Access This article is licensed under a Creative Commons Attribution 4.0 International License, which permits use, sharing, adaptation, distribution and reproduction in any medium or format, as long as you give appropriate credit to the original author(s) and the source, provide a link to the Creative Commons licence, and indicate if changes were made. The images or other third party material in this article are included in the article's Creative Commons licence, unless indicated otherwise in a credit line to the material. If material is not included in the article's Creative Commons licence and your intended use is not permitted by statutory regulation or exceeds the permitted use, you will need to obtain permission directly from the copyright holder. To view a copy of this licence, visit http://creativecommons.org/licenses/by/4.0/ The Creative Commons Public Domain Dedication waiver (http://creativecommons.org/publicdomain/zero/1.0/) applies to the data made available in this article, unless otherwise stated in a credit line to the data. 
(Continued from previous page)

Results: Evidence from the literature reviews provided substantial support for the importance of family on children's movement behaviours and highlighted the importance of inclusion of the entire family system as a source of influence and promotion of healthy child and youth movement behaviours. The Expert Panel incorporated the collective evidence from all reviews, the custom analyses, other related research identified, and stakeholder survey feedback, to develop a conceptual model and arrive at the Consensus Statement: Families can support children and youth in achieving healthy physical activity, sedentary and sleep behaviours by encouraging, facilitating, modelling, setting expectations and engaging in healthy movement behaviours with them. Other sources of influence are important (e.g., child care, school, health care, community, governments) and can support families in this pursuit.

Conclusion: Family is important for the support and promotion of healthy movement behaviours of children and youth. This Consensus Statement serves as a comprehensive, credible, and current synopsis of related evidence, recommendations, and resources for multiple stakeholders.

Keywords: Parent, Guardian, Sibling, Role model, Support, Physical activity, Sleep, Sedentary behaviours, Rules, Parenting practices, Structure, Health

\section{Background}

The Canadian 24-Hour Movement Guidelines were recently developed to provide public health guidelines integrating recommendations for physical activity, sedentary, and sleep behaviours for the pediatric population ranging from 0 to 4 years and 5 to 17 years $[1,2]$. Children and youth who adhere to these guidelines are more likely to display healthy growth, body composition, cardiorespiratory and musculoskeletal fitness, cardiovascular and metabolic health, motor development, cognitive development, academic achievement, emotional regulation, pro-social behaviours, and overall quality of life [3-12]. Furthermore, healthy movement behaviours in childhood are associated with a higher likelihood of healthy physical activity [13], sedentary [14], and sleep [15] behaviours in later adolescence or adulthood and their commensurate positive health outcomes [16, 17].

Because of the unequivocal holistic health benefits of healthy movement behaviours during childhood and adolescence, several authoritative groups around the world have released, endorsed or promoted evidencebased movement guidelines and recommendations to inform the public $[1,2,18-31]$. A sample of these guidelines, resources and links are summarized in Table 1 to demonstrate the consistency of recommendations and the rapid global adoption of the 24-h movement paradigm. In essence, these guidelines from many countries and jurisdictions recommend that children move more, sit less, limit recreational screen-time, and preserve a good night's sleep every day. The Canadian 24-h movement guidelines $[1,2]$ were the first such guidelines and are highlighted in bold in Table 1.

Many studies have shown that health benefits accumulate with each additional movement guideline met (i.e., physical activity, sedentary behaviour/screen-time, sleep) [9, 32-37]. Unfortunately, among Canadian children, only $13 \%$ of $3-4-$ year-olds [9], $17 \%$ of $5-17$ year-olds [9, 38 ], and $3 \%$ of $11-15$ year-olds [34] adhere to the Canadian 24-Hour Movement Guidelines [1, 2]. Similar low adherence to healthy movement behaviour recommendations among children and youth have been reported in samples from Australia [39], Belgium [40], Mozambique [41], New Zealand [42], Sweden [43], the United Kingdom [44], the United States [37, 45, 46], and even lower adherences in China [35], Singapore [47] and South Korea [36]. Clearly, the need to promote healthy movement behaviours among children and youth is a worldwide public health priority.

The promotion of increased physical activity, decreased sedentary behaviour, and good sleep hygiene (e.g., routines and practices that are conducive to sleeping well) can occur in multiple settings, such as in childcare [48], at school [49], and within the community [50, 51]. Children and youth also spend considerable time with siblings and in the care of their parents or legal guardians, suggesting family-based initiatives are likely central to improving movement behaviours at the population level. Family influence (e.g., parents, guardians, siblings) on physical activity [52], sedentary behaviour [53], and sleep [54] has received considerable research attention. Family influence on a child can take many forms, such as modelling [55], encouragement [56], logistical support [57], rules and restrictions [54], coparticipation [58], and spectating/supervision [59]. Parenting practices that influence child and youth health behaviours include components of responsiveness (providing encouragement and autonomy), structure (providing social and physical environments) and demandingness (restrictive and punitive practices) [60, 61]. Family systems and behaviours are complex; the family unit is in a constant cycle of interactions among members, with evolution and change being inherent 
Table 1 Movement Behaviour Guidelines for Children and Youth (ages 0-17 years) from different authoritative organizations

\begin{tabular}{|c|c|c|c|c|c|c|}
\hline $\begin{array}{l}\text { Authoritative } \\
\text { Organization and } \\
\text { Reference }\end{array}$ & Country & Age Group & $\begin{array}{l}\text { Recommendation } \\
\text { PHYSICAL ACTIVITY }\end{array}$ & $\begin{array}{l}\text { Recommendation } \\
\text { SCREENTIME/ } \\
\text { SEDENTARY TIME }\end{array}$ & $\begin{array}{l}\text { Recommendation } \\
\text { SLEEP }\end{array}$ & Additional Notes \\
\hline
\end{tabular}

American Academy of USA $0-1.5$ yrs Avoid digital media

Pediatrics Council on

Communications and

Media. 2016 [24]

For children 2 to 5 yrs. of age, limit screen use to $1 \mathrm{~h}$ per day of highquality programming.
For children ages 18 to 24 months of age, if you want to introduce digital media, choose high-quality programming and use media together with your child.

Avoid solo media use in this age group.

Use the Family Media Use Plan (www. healthychildren.org/ MediaUsePlan) with specific guidelines for each child and parent.

Create unplugged spaces and times in homes.

Use new technologies in social and creative ways.

Stress the importance of not displacing sleep, exercise, play, reading aloud, and social interaction with screen use.

Recommend no screens during meals and for $1 \mathrm{~h}$ before bedtime. Remove devices from bedrooms before bed. For children 2-5yrs. of age, limit screen use to $1 \mathrm{~h}$ per day of highquality programming, co-view with your children, help children understand what they are seeing, and help them apply what they learn.

Monitor children's media content and what apps are used or downloaded. Test apps before the child uses them, play together, and ask the child what they think about the app.

Keep bedrooms, mealtimes, and parentchild playtimes screenfree for children and parents. Parents can set a "do not disturb" option on their phones 
Table 1 Movement Behaviour Guidelines for Children and Youth (ages 0-17 years) from different authoritative organizations (Continued)

\begin{tabular}{llllll}
\hline $\begin{array}{l}\text { Authoritative } \\
\text { Organization and } \\
\text { Reference }\end{array}$ & Country & Age Group & $\begin{array}{l}\text { Recommendation } \\
\text { PHYSICAL ACTIVITY }\end{array}$ & $\begin{array}{l}\text { Recommendation } \\
\text { SCREENTIME/ } \\
\text { SEDENTARY TIME }\end{array}$ & $\begin{array}{l}\text { Recommendation } \\
\text { SLEEP }\end{array}$
\end{tabular}

American Academy of Sleep Medicine. 2016 [20]



Australian 24-Hour Movement Guidelines Australia $0-1 \mathrm{yr}$ for the Early Years (Birth to 5 years): An Integration of Physical Activity, Sedentary Behaviour, and Sleep. 2017 [23]

Australia $0-1$ yr
several times in a variety of ways, particularly through interactive floor-based play; more is better. For those not yet mobile, this includes at least 30 min of tummy time spread throughout the day while awake.
At least 180 min spent in a variety of physical activities at any intensity, spread throughout the day; more is better. Including energetic play.
At least 180 min spent
Being physically active

Infants* 4 months to 12 months should sleep 12 to $16 \mathrm{~h}$ per $24 \mathrm{~h}$ (including naps).

11 to $14 \mathrm{~h}$ per $24 \mathrm{~h}$ (including naps)

Not being restrained for more than $1 \mathrm{~h}$ at a time (e.g., in a stroller, car seat or high chair). When sedentary, engaging in pursuits such as reading and storytelling with a caregiver is encouraged. Screen-time is not recommended.

Not being restrained for more than $1 \mathrm{~h}$ at a time (e.g., in a stroller, car seat or high chair) or sitting for extended periods. When sedentary, engaging in pursuits such as reading and storytelling with a caregiver is encouraged. For those younger than 2 yrs., sedentary screen-time is not recommended. For those aged 2 yrs., sedentary screen-time should be no more than $1 \mathrm{~h}$ per day; less is better. in a variety of physical

10 to $13 \mathrm{~h}$ per $24 \mathrm{~h}$ (including naps)

9 to $12 \mathrm{~h}$ per $24 \mathrm{~h}$

8 to $10 \mathrm{~h}$ per $24 \mathrm{~h}$

14 to $17 \mathrm{~h}$ (for those aged 0-3 months) of good quality sleep, including naps.

12 to $16 \mathrm{~h}$ (for those good quality sleep, including naps.

11 to $14 \mathrm{~h}$ of good naps, with consistent sleep and wakeup times.

Not being restrained for more than $1 \mathrm{~h}$ at a during these times. Avoid fast-paced programs (young children do not understand them as well), apps with lots of distracting content, and any violent content. Turn off TVs and other devices when not in use.

*Recommendations for infants younger than 4 months are not included due to the wide range of normal variation in duration and patterns of sleep, and insufficient evidence for associations with health outcomes. aged 4-11 months) of quality sleep, including
10 to $13 \mathrm{~h}$ of good quality sleep, which 
Table 1 Movement Behaviour Guidelines for Children and Youth (ages 0-17 years) from different authoritative organizations (Continued)

\begin{tabular}{|c|c|c|c|c|c|}
\hline $\begin{array}{l}\text { Authoritative } \\
\text { Organization and } \\
\text { Reference }\end{array}$ & Country Age Group & $\begin{array}{l}\text { Recommendation } \\
\text { PHYSICAL ACTIVITY }\end{array}$ & $\begin{array}{l}\text { Recommendation } \\
\text { SCREENTIME/ } \\
\text { SEDENTARY TIME }\end{array}$ & $\begin{array}{l}\text { Recommendation } \\
\text { SLEEP }\end{array}$ & Additional Notes \\
\hline & & $\begin{array}{l}\text { activities spread } \\
\text { throughout the day, } \\
\text { of which at least } 60 \\
\text { min is energetic play; } \\
\text { more is better. }\end{array}$ & $\begin{array}{l}\text { time (e.g., in a stroller } \\
\text { or car seat). Avoid } \\
\text { sitting for extended } \\
\text { periods. When } \\
\text { sedentary, engaging in } \\
\text { pursuits such as } \\
\text { reading and } \\
\text { storytelling with a } \\
\text { caregiver is } \\
\text { encouraged. } \\
\text { Sedentary screen-time } \\
\text { should be no more } \\
\text { than } 1 \mathrm{~h} \text { per day; less is } \\
\text { better. }\end{array}$ & $\begin{array}{l}\text { may include a nap, } \\
\text { with consistent sleep } \\
\text { and wakeup times. }\end{array}$ & \\
\hline
\end{tabular}

Australian Department Australia 5-13 yrs

of Health. Australian

24-Hour Movement

Guidelines for Children

and Young People (5-

17 years) - An Integra-

tion of Physical Activity,

Sedentary Behaviour

and Sleep. 2019. Avail-

able from: https://

www1.health.gov.au/

internet/main/publish-

ing.nsf/Content/

health-24-hours-phys-

act-guidelines [25]

Canadian 24-Hour

Movement Guidelines

for the Early Years

(0-4 years): An Inte-

gration of Physical

Activity, Sedentary

Behaviour, and Sleep.

2017 [2]

Canada $\quad 0-1 \mathrm{yr}$
Accumulating $60 \mathrm{~min}$ or more of MVPA per day involving mainly aerobic activities.

Activities that are

vigorous, as well as

14-17 yrs those that strengthen

muscle and bone

should be

incorporated at least 3

days per week.

Several hrs of a variety

of light physical

activities.

Being physically active several times in a variety of ways, particularly through interactive floorbased play; more is better.

For those not yet mobile, this includes at least $30 \mathrm{~min}$ of tummy time spread throughout the day while awake.

1-2 yrs At least $180 \mathrm{~min}$ spent in a variety of physical activities at any intensity, including energetic play, spread throughout the day

- more is better.
Limiting sedentary recreational screentime to no more than $2 \mathrm{~h}$ per day.

Breaking up long periods of sitting as often as possible.

Not being restrained for more than $1 \mathrm{~h}$ at a time (e.g., in a stroller or high chair). Screen-time is not recommended. When sedentary, engaging in pursuits such as reading and storytelling with a caregiver is encouraged.

Not being restrained for more than $1 \mathrm{~h}$ at a time (e.g., in a stroller or high chair) or sitting for extended periods. For those younger than $2 \mathrm{yrs}$, sedentary screen-time is not recommended. For those aged 2 yrs, sedentary screentime should be no more than $1 \mathrm{~h}$; less is better.

When sedentary, engaging in pursuits such as reading and storytelling with a caregiver is encouraged.
An uninterrupted 9 to $11 \mathrm{~h}$ of sleep per night for those aged 5-13 yrs.

Consistent bed and wake-up times.

For greater health benefits, replace sedentary time with additional MVPA, while preserving sufficient sleep.
8 to $10 \mathrm{~h}$ per night for those aged 14-17 yrs. Consistent bed and wake-up times.
14-17 h (for those aged 0-3 months) or 12-16 $\mathrm{h}$ (for those aged 4-11 months) of good-quality sleep, including naps.

11-14 h of goodquality sleep, including naps, with consistent bedtimes and wake-up times. 
Table 1 Movement Behaviour Guidelines for Children and Youth (ages 0-17 years) from different authoritative organizations (Continued)

\begin{tabular}{|c|c|c|c|c|c|c|}
\hline $\begin{array}{l}\text { Authoritative } \\
\text { Organization and } \\
\text { Reference }\end{array}$ & Country & Age Group & $\begin{array}{l}\text { Recommendation } \\
\text { PHYSICAL ACTIVITY }\end{array}$ & $\begin{array}{l}\text { Recommendation } \\
\text { SCREENTIME/ } \\
\text { SEDENTARY TIME }\end{array}$ & $\begin{array}{l}\text { Recommendation } \\
\text { SLEEP }\end{array}$ & Additional Notes \\
\hline & & $3-4$ yrs & $\begin{array}{l}\text { At least } 180 \text { min } \\
\text { spent in a variety of } \\
\text { physical activities } \\
\text { spread throughout } \\
\text { the day, of which at } \\
\text { least } 60 \text { min is } \\
\text { energetic play } \\
\text { - more is better. }\end{array}$ & $\begin{array}{l}\text { Not being restrained } \\
\text { for more than } 1 \mathrm{~h} \text { at } \\
\text { a time (e.g., in a } \\
\text { stroller or car seat) or } \\
\text { sitting for extended } \\
\text { periods. } \\
\text { Sedentary screen- } \\
\text { time should be no } \\
\text { more than } 1 \mathrm{~h} \text {; less is } \\
\text { better. } \\
\text { When sedentary, } \\
\text { engaging in pursuits } \\
\text { such as reading and } \\
\text { storytelling with a } \\
\text { caregiver is } \\
\text { encouraged. }\end{array}$ & $\begin{array}{l}10-13 \mathrm{~h} \text { of good- } \\
\text { quality sleep, which } \\
\text { may include a nap, } \\
\text { with consistent bed- } \\
\text { times and wake-up } \\
\text { times. }\end{array}$ & \\
\hline
\end{tabular}

Canadian 24-Hour

for Children and

$\begin{array}{ll}\text { Canada } & \text { 5-13 yrs } \\ & 14-17 \mathrm{yrs}\end{array}$

of Physical Activity,

Sedentary Behaviour, and Sleep. 2016

[1]
An accumulation of No more than $2 \mathrm{~h}$ / at least $60 \mathrm{~min} /$ day of MVPA involving a variety of aerobic activities. Vigorous physical activity and muscle and bone strengthening activities should each be incorporated at least 3 days/wk. Several hours of a variety of structured and unstructured light physical activities. screen-time. Limited sitting for extended periods.



\section{No more than $2 \mathrm{~h} /$
day of recreational}

9-11 h

8-10h

Screen-time for

children younger than

2 yrs. is not

recommended.

For children 2 to 5 yrs., limit routine or regular screen-time to less than $1 \mathrm{~h}$ per day.
Preserving sufficient sleep, trading indoor for outdoor time, and replacing sedentary behaviours and light physical activity with additional MVPA can provide greater health benefits.
Ensure that sedentary screen-time is not a routine part of childcare for children younger than 5 yrs.

Maintain daily 'screenfree' times, especially for family meals and book-sharing. Avoid screens for at least $1 \mathrm{~h}$ before bedtime, given the potential for melatonin-suppressing effects.

Be present and engaged when screens are used and

whenever possible, coview with children. Be aware of content and prioritize educational, ageappropriate and interactive programming. Use parenting strategies that teach self-regulation, calming and limit-setting.

Choose healthy alternatives, such as 
Table 1 Movement Behaviour Guidelines for Children and Youth (ages 0-17 years) from different authoritative organizations (Continued)

\begin{tabular}{|c|c|c|c|c|c|c|}
\hline $\begin{array}{l}\text { Authoritative } \\
\text { Organization and } \\
\text { Reference }\end{array}$ & Country & Age Group & $\begin{array}{l}\text { Recommendation } \\
\text { PHYSICAL ACTIVITY }\end{array}$ & $\begin{array}{l}\text { Recommendation } \\
\text { SCREENTIME/ } \\
\text { SEDENTARY TIME }\end{array}$ & $\begin{array}{l}\text { Recommendation } \\
\text { SLEEP }\end{array}$ & Additional Notes \\
\hline
\end{tabular}

Children and Screens: USA

Institute of Digital

Media and Child

Development, 2017

https://www.

childrenandscreens.

com/findings/ [27]
$4-13$ yrs

Newborns

0-3 months
National Sleep

Foundation's updated

sleep duration

recommendations: final

report. 2015 [21]

USA

Infants (4-

11 months)

Toddlers (1-

2yrs)

Preschoolers

(3-5 yrs)

School-aged

children (6-

13 yrs)

Teenagers

(14-17yrs)

New Zealand Ministry of Health. Sit Less,

New

$0-1 \mathrm{yr}$

Zealand
Limiting TV exposure (especially background TV) before the age of 2 yrs.

Limit total screen-time, TV watching, video game playing, and computer use (excluding computer use for school homework, when applicable) no more than $7 \mathrm{~h}$ per week.

reading, outdoor play, and creative, hands-on activities.

Turn off devices at home during family time.

Turn off screens when not in use and avoid background TV.

Plan a bedtime that allows for adequate sleep.

Use a bedtime routine that includes calming activities and avoids electronic media use. Limit media use in the hour or two before bedtime.

Turn off electronic media devices in the evening and charge them in a central location outside bedrooms.

Be a healthy sleep and media role model for your child or adolescent.

Remove all electronic media from your child or teen's bedroom, including TVs, video games, computers, tablets, and cell phones.

Turn mobile devices off during class and other learning activities. Turn TV off during schoolwork time. Turn TV off when no one is watching.

14-17 h

$12-15 \mathrm{~h}$

$11-14 \mathrm{~h}$

10-13 h

9-11 h

$8-10 \mathrm{~h}$

Discourage screen-time Babies (birth to 3 months) should have 14 to $17 \mathrm{~h}$ goodquality sleep every
Provide regular activity breaks to limit the amount of time a child spends sitting. 
Table 1 Movement Behaviour Guidelines for Children and Youth (ages 0-17 years) from different authoritative organizations (Continued)

\begin{tabular}{|c|c|c|c|c|}
\hline $\begin{array}{l}\text { Authoritative } \\
\text { Organization and } \\
\text { Reference }\end{array}$ & Country Age Group & $\begin{array}{l}\text { Recommendation } \\
\text { PHYSICAL ACTIVITY }\end{array}$ & $\begin{array}{l}\text { Recommendation } \\
\text { SCREENTIME/ } \\
\text { SEDENTARY TIME }\end{array}$ & $\begin{array}{l}\text { Recommendation } \\
\text { SLEEP }\end{array}$ \\
\hline $\begin{array}{l}\text { for Under-Fives. } 2017 \\
\text { [29] }\end{array}$ & & & & $\begin{array}{l}\text { day, including daytime } \\
\text { sleeps centred around } \\
\text { their physical and } \\
\text { emotional needs. } \\
\text { Infants (4-12 months) } \\
\text { should have } 12 \text { to } 15 \mathrm{~h} \\
\text { good-quality sleep } \\
\text { every day, including } \\
\text { daytime sleeps, which } \\
\text { will tend to decrease } \\
\text { as they get closer to } 1 \\
\text { yr of age. }\end{array}$ \\
\hline
\end{tabular}

Additional Notes

Organization and

yr of age.

$$
1-2 \mathrm{yrs}
$$

2 yrs. and older

\footnotetext{
U.K. Chief Medical
} Officers' Physical

UK $\quad 0-1 \mathrm{yr}$
Discourage screen-time for under-2-yr-olds and limit screen-time to less than $1 \mathrm{~h}$. every day for children aged 2 yrs. or older - less is best! Limit time in equipment that restricts free movement. From birth, encourage regular, unrestricted floor-based play (tummy time), on a safe surface.

Be a role model: reduce your own screen use. Replace TV time with reading time, story time or doing jigsaw puzzles together. Avoid having the TV playing in the background. Remove the TV completely or limit having it on until the children have gone to bed.

Do not have screens in (any) bedrooms. Set limited viewing times for all screens. Store DVDs, consoles, tablets and electronic games out of sight. Break up long car journeys with regular stops (preferably at least once an hr), removing under-fives from their capsule/car seat at each stop. Encourage toddlers and preschoolers to walk instead of being in a pushchair.
At least $3 \mathrm{~h}$ every day for toddlers and preschoolers, spread throughout the day.

At least $3 \mathrm{~h}$ every day for toddlers and preschoolers, spread throughout the day.

Less than $1 \mathrm{~h}$ every

day

Infants should be

physically active time.

\section{Discourage screen- $\quad$ Toddlers (1 to 2 yrs.} inclusive) should have 11 to $14 \mathrm{~h}$ of goodquality sleep every day, including at least one daytime sleep.

Preschoolers (3 to 4 yrs. inclusive) should have 10 to $13 \mathrm{~h}$ of good-quality sleep every day, with consistent bedtimes and wake-up times. 
Table 1 Movement Behaviour Guidelines for Children and Youth (ages 0-17 years) from different authoritative organizations (Continued)

\begin{tabular}{|c|c|c|c|c|c|c|}
\hline $\begin{array}{l}\text { Authoritative } \\
\text { Organization and } \\
\text { Reference } \\
\end{array}$ & Country & Age Group & $\begin{array}{l}\text { Recommendation } \\
\text { PHYSICAL ACTIVITY }\end{array}$ & $\begin{array}{l}\text { Recommendation } \\
\text { SCREENTIME/ } \\
\text { SEDENTARY TIME }\end{array}$ & $\begin{array}{l}\text { Recommendation } \\
\text { SLEEP }\end{array}$ & Additional Notes \\
\hline \multirow[t]{4}{*}{$\begin{array}{l}\text { Activity Guidelines, } \\
2019[22,30] .\end{array}$} & & & $\begin{array}{l}\text { several times every day } \\
\text { in a variety of ways, } \\
\text { including interactive } \\
\text { floor-based activity, e.g. } \\
\text { crawling. } \\
\text { For infants not yet } \\
\text { mobile, this includes at } \\
\text { least } 30 \text { min of tummy } \\
\text { time spread } \\
\text { throughout the day } \\
\text { while awake (and } \\
\text { other movements such } \\
\text { as reaching and } \\
\text { grasping, pushing and } \\
\text { pulling themselves } \\
\text { independently, or } \\
\text { rolling over); more is } \\
\text { better. } \\
\text { Tummy time may be } \\
\text { unfamiliar to babies at } \\
\text { first, but can be } \\
\text { increased gradually, } \\
\text { starting from a min or } \\
\text { two at a time, as the } \\
\text { baby becomes used to } \\
\text { it. Babies should not } \\
\text { sleep on their } \\
\text { tummies. }\end{array}$ & & & \\
\hline & & $1-2 \mathrm{yrs}$ & $\begin{array}{l}\text { Toddlers should spend } \\
\text { at least } 180 \text { min ( } 3 \text { h) } \\
\text { per day in a variety of } \\
\text { physical activities at } \\
\text { any intensity, including } \\
\text { active and outdoor } \\
\text { play, spread } \\
\text { throughout the day; } \\
\text { more is better. }\end{array}$ & & & \\
\hline & & $3-4$ yrs & $\begin{array}{l}\text { Preschoolers should } \\
\text { spend at least } 180 \text { min } \\
\text { ( } 3 \text { h) per day in a } \\
\text { variety of physical } \\
\text { activities spread } \\
\text { throughout the day, } \\
\text { including active and } \\
\text { outdoor play. More is } \\
\text { better; the } 180 \text { min } \\
\text { should include at least } \\
60 \text { min of MVPA. }\end{array}$ & & & \\
\hline & & $5-18 y r s$ & $\begin{array}{l}\text { Children and young } \\
\text { people should engage } \\
\text { in MVPA for an } \\
\text { average of at least } 60 \\
\text { min per day across the } \\
\text { week. This can include } \\
\text { all forms of activity } \\
\text { such as physical } \\
\text { education, active } \\
\text { travel, after-school ac- } \\
\text { tivities, play and sports. }\end{array}$ & & & $\begin{array}{l}\text { Children and young } \\
\text { people should engage } \\
\text { in a variety of types } \\
\text { and intensities of } \\
\text { physical activity across } \\
\text { the week to develop } \\
\text { movement skills, } \\
\text { muscular fitness, and } \\
\text { bone strength. } \\
\text { Children and young } \\
\text { people should aim to } \\
\text { minimize the amount } \\
\text { of time spent being } \\
\text { sedentary, and when } \\
\text { physically possible }\end{array}$ \\
\hline
\end{tabular}


Table 1 Movement Behaviour Guidelines for Children and Youth (ages 0-17 years) from different authoritative organizations (Continued)

\begin{tabular}{llllll}
\hline Authoritative & Country & Age Group & Recommendation \\
Organization and & & PHYSICAL ACTIVITY & Recommendation & Recommendation & Additional Notes \\
Reference & & & SEDENTIME/ & SLEEP
\end{tabular}
SEDENTARY TIME

\begin{abstract}
U.S. Department of Health and Human Services. Physical Activity Guidelines for Americans. 2nd ed.
\end{abstract} 2018 [31]
World Health

Organization. WHO

Guidelines on Physical

Activity, Sedentary

Behaviour and Sleep

for Children Under 5

Years of Age. 2019 [18]

\section{USA $\quad 3-5$ yrs}



and

\section{targ} efined, a reasonable target may be $3 \mathrm{~h}$ per day of activity of all intensities: light, moderate, or vigorous intensity.

6-17yrs Children and adolescents ages 6 through $17 \mathrm{yrs}$. should do 60 min (1 h) or more of MVPA daily. Aerobic: Most of the 60 min or more per day should be either moderate- or vigorousintensity aerobic physical activity and should include vigorousintensity physical activity on at least 3 days a week.

Muscle-strengthening: As part of their $60 \mathrm{~min}$ or more of daily physical activity, children and adolescents should include musclestrengthening physical activity on at least 3 days a week. Bone-strengthening: As part of their 60 min or more of daily physical activity, children and adolescents should include bonestrengthening physical activity on at least 3 days a week.

Be physically active several times a day in a variety of ways, particularly through interactive floor-based play; more is better. For those not yet mobile, this includes at least $30 \mathrm{~min}$ in prone position (tummy time) spread throughout the day while awake.
Not be restrained for more than $1 \mathrm{~h}$ at a time (e.g. prams/ strollers, highchairs, or strapped on a caregiver's back).

Screen-time is not recommended. When sedentary, engaging in reading and storytelling with a caregiver is encouraged. should break up long periods of not moving with at least light physical activity.

The Advisory Committee did not review evidence for children younger than age 3 yrs.
Have 14-17 h (0-3 months of age) or 12$16 \mathrm{~h}$ (4-11 months of age) of good quality sleep, including naps. 
Table 1 Movement Behaviour Guidelines for Children and Youth (ages 0-17 years) from different authoritative organizations (Continued)

\begin{tabular}{|c|c|c|c|c|c|c|}
\hline $\begin{array}{l}\text { Authoritative } \\
\text { Organization and } \\
\text { Reference }\end{array}$ & Country & Age Group & $\begin{array}{l}\text { Recommendation } \\
\text { PHYSICAL ACTIVITY }\end{array}$ & $\begin{array}{l}\text { Recommendation } \\
\text { SCREENTIME/ } \\
\text { SEDENTARY TIME }\end{array}$ & $\begin{array}{l}\text { Recommendation } \\
\text { SLEEP }\end{array}$ & Additional Notes \\
\hline & & $1-2$ yrs & $\begin{array}{l}\text { Spend at least } 180 \text { min } \\
\text { in a variety of types of } \\
\text { physical activities at } \\
\text { any intensity, including } \\
\text { MVPA, spread } \\
\text { throughout the day; } \\
\text { more is better. }\end{array}$ & $\begin{array}{l}\text { Not be restrained for } \\
\text { more than } 1 \mathrm{~h} \text { at a } \\
\text { time (e.g., prams/ } \\
\text { strollers, highchairs, or } \\
\text { strapped on a } \\
\text { caregiver's back) or sit } \\
\text { for extended periods } \\
\text { of time. } \\
\text { For } 1 \text {-yr-olds, sedentary } \\
\text { screen-time (such as } \\
\text { watching TV or videos, } \\
\text { playing computer } \\
\text { games) is not } \\
\text { recommended. } \\
\text { For those aged } 2 \text { yrs., } \\
\text { sedentary screen-time } \\
\text { should be no more } \\
\text { than } 1 \text { h; less is better. } \\
\text { When sedentary, } \\
\text { engaging in reading } \\
\text { and storytelling with a } \\
\text { caregiver is } \\
\text { encouraged. }\end{array}$ & $\begin{array}{l}\text { Have } 11-14 \mathrm{~h} \text { of good } \\
\text { quality sleep, including } \\
\text { naps, with regular } \\
\text { sleep and wake-up } \\
\text { times. }\end{array}$ & \\
\hline & & $3-4$ yrs & $\begin{array}{l}\text { Spend at least } 180 \text { min } \\
\text { in a variety of types of } \\
\text { physical activities at } \\
\text { any intensity, of which } \\
\text { at least } 60 \text { min is } \\
\text { MVPA, spread } \\
\text { throughout the day; } \\
\text { more in better. }\end{array}$ & $\begin{array}{l}\text { Not be restrained for } \\
\text { more than } 1 \mathrm{~h} \text { at a } \\
\text { time (e.g. prams/ } \\
\text { strollers) or sit for } \\
\text { extended periods of } \\
\text { time. Sedentary screen- } \\
\text { time should be no } \\
\text { more than } 1 \mathrm{~h} \text {; less is } \\
\text { better. When seden- } \\
\text { tary, engaging in read- } \\
\text { ing and storytelling } \\
\text { with a caregiver is } \\
\text { encouraged. }\end{array}$ & $\begin{array}{l}\text { Have } 10-13 \text { h of good } \\
\text { quality sleep, which } \\
\text { may include a nap, } \\
\text { with regular sleep and } \\
\text { wake-up times. }\end{array}$ & \\
\hline $\begin{array}{l}\text { World Health } \\
\text { Organization. Global } \\
\text { Recommendation on } \\
\text { Physical Activity for } \\
\text { Health. } 2010 \text { [19] }\end{array}$ & Global & $5-17 y r s$ & $\begin{array}{l}\text { At least } 60 \text { min of } \\
\text { MVPA daily. } \\
\text { Most of daily physical } \\
\text { activity should be } \\
\text { aerobic. } \\
\text { Vigorous-intensity } \\
\text { activities should be } \\
\text { incorporated, including } \\
\text { those that strengthen } \\
\text { muscle and bone, at } \\
\text { least } 3 \text { times per week. }\end{array}$ & & & \\
\hline
\end{tabular}

Note: Min minutes; Hrs hours; Yrs years; MVPA moderate-to-vigorous intensity physical activity

[62-64]. Family membership can vary considerably, as can roles and responsibilities; however, parents (or legal guardians) have unique legal responsibilities, liabilities, and decision-making authority.

With constantly changing environments (including practices, policies, social norms, built features, technology) at home, childcare centres, schools and in communities, coupled with the new paradigm of integrated movement behaviours $[1,2]$, the challenges for achieving healthy movement behaviours can be overwhelming for families and those who support them (e.g., public health professionals, health care providers, teachers, policymakers). Accordingly, a comprehensive process was initiated in Canada to develop and release an Consensus Statement on the Role of the Family in the Physical Activity, Sedentary, and Sleep Behaviours of Children and Youth (0-17 years) to consolidate related evidence, highlight key facts, and provide guidance to families and those who support families on how to promote regular healthy movement behaviours of children and youth. The process and this manuscript were modelled after similar initatives that proved to be successful and well- 
received by the academic community (all cited $>100$ times according to Scopus [1, 2, 65-69]). The purpose of this manuscript is to describe the process used to develop the Consensus Statement and present, explain, substantiate, and discuss the final Consensus Statement.

\section{Methods}

Active Healthy Kids Canada and ParticipACTION (Canadian not-for-profit organizations) have been producing Canadian Report Cards on Physical Activity for Children and Youth since 2005 [70-74]. These Report Cards provide a public-facing synthesis of the best available evidence of how Canada is doing across a range of indicators related to movement behaviours, and the settings and sources of influence that serve as barriers or enablers of these behaviours. In recent years, the Report Card has also served as an effective dissemination and distribution vehicle for additional "knowledge products". These knowledge products serve as complementary adjuncts to the Report Card but are also stand-alone resources. Previous knowledge products have included the Global Matrix in 2014 [75], the Active Outdoor Play Position Statement in 2015 [76], the Canadian 24-Hour Movement Guidelines for Children and Youth in 2016 [1], and the Expert Statement on Physical Activity and Brain Health in Children and Youth in 2018 (https:// www.participaction.com/en-ca/resources/report-card). This Consensus Statement on the Role of the Family in the Physical Activity, Sedentary, and Sleep Behaviours of Children and Youth is the latest in this list of knowledge products and is contained within the 2020 ParticipACTION Report Card on Physical Activity for Children and Youth [77].

This project was initiated in partnership by ParticipACTION and the Healthy Active Living and Obesity Research Group (HALO) at the Children's Hospital of Eastern Ontario (CHEO) Research Institute. The development and release of the 2020 Consensus Statement included the establishment of a multi-disciplinary Expert Panel, completion of six reviews (three literature, two scoping, and one review of reviews), custom data analyses from Statistics Canada's Canadian Health Measures Survey (CHMS), integration of related research identified by Expert Panel members, a stakeholder consultation process, establishment of consensus, and the development of a media, public relations, communications and launch plan.

To establish the Expert Panel, the project leaders (MST, LMV, RER) created a list of experts in the field of children's movement behaviours, family health research, advocates and thought leaders in these areas. Email invitations were used to recruit Expert Panel members. While the project was Canadian led and Canadian focussed, two international candidates with prominent research profile in this area were also invited to join the Expert Panel and provide an international perspective.

The six reviews were undertaken to help inform the Consensus Statement after initial consultation with the multi-disciplinary Expert Panel. The first three reviews (reviews \#1-3) were conducted 9 months prior to the last three reviews (reviews \#4-6). Findings from reviews \#1-3 were used to determine whether there was sufficient evidence on family and children's movement behaviours, and whether the Expert Panel was in a position to write a consensus statement on this topic. Members of the Expert Panel reviewed the findings from reviews \#1-3 and agreed to proceed with reviews \#4-6. Team members responsible for conducting reviews \#1-3 differed from those responsible for conducting reviews \#46. This approach was taken in order to draw on the different expertise and experience of team members and to share workload burden. Nevertheless, all reviews followed the basic PRISMA statements for reporting reviews $[78,79]$. The overall purposes of the systematic literature reviews were to: i) examine the breadth of existing research on family and children and youth's physical activity, sedentary, and sleep behaviours, and categorize articles by type of familial influence, ii) synthesize findings of frequently researched themes within each movement behaviour, iii) provide an overview of family-systems based theories used in the disciplines of psychology, sociology, and/or social work; iv) provide an overview of family-based theories or family behavioural models used to understand child health behaviour change, v) identify significant correlates of parental support of child and youth healthy 24-h movement behaviours, and vi) evaluate the efficacy of child and youth interventions focused on changes in physical activity, sedentary and/or sleep behaviours, where at least one parent was involved in the intervention. Therefore, the six reviews investigated the evidence on: i) family influences and characteristics and children and youth's physical activity behaviours (review \#1); ii) family characteristics and children and youth's sedentary behaviours and screen-time behaviours (review \#2); iii) family characteristics and children and youth's sleep behaviours (review \#3); iv) family systems approaches applied to understand 24-h movement behaviours among children and youth (review \#4); v) correlates of parental support of child and youth 24-h movement behaviours (review \#5); and, vi) family-based interventions on children and youth 24-h movement behaviours (review \#6).

To better understand the relationships between family structure and child movement behaviours in Canada, custom analyses from Statistics Canada's CHMS [80] were requested. The CHMS is a large, nationally representative repeated cross-sectional survey of Canadians aged 3-79 years that gathers directly measured health 
data on Canadians in two-year cycles. Data are gathered through a detailed health interview and a visit to a mobile examination centre where several direct measures of health are taken (e.g., anthropometry, physical fitness, accelerometry-measured physical activity and sedentary behaviour, blood pressure; and biospecimen collection for analysis of chronic and infectious disease biomarkers, nutritional status, and environmental exposures). Complete details of the CHMS are available at https:// www23.statcan.gc.ca/imdb/p2SV.pl?Function=getSurvey\&SDDS=5071). Analyses obtained included merged data from cycles $1-5(2007-2017)$ that described relationships between accelerometer-measured variables (including average minutes per day of moderate-tovigorous physical activity [MVPA], light physical activity, sedentary time, and step counts) by number of children in the household and single- versus two-parent households, by age groups (5-11 [cycle $2-5$ only] and 12-17 years) and sex. Similar analyses were also obtained for self-reported sleep duration, screen-time and physical activity domains (active transportation, recreational physical activity, occupational/household physical activity); however, adult and youth results are from cycles 45 combined only, and children and preschoolers results are from cycles $2,3,4$, and 5 combined. Screen-time results included cycles 2, 3, 4 only due to a response option change in cycle 5 that makes it non-comparable to previous cycles. The CHMS also samples same-family parent-child dyads in approximately one fifth of the sample in each cycle. Recently, findings from the dyad file comparing parent-child physical activity, screen-time and fitness were also gathered.

A small Steering Committee with four representatives (RER, MDG, LMV, MST) from the larger Expert Panel was formed to organize the work plan, complete the reviews, draft the Consensus Statement and related manuscript, and report back to the multi-disciplinary Expert Panel. Expert Panel members were selected based on their research, practice, and/or professional experience related to the 24-Hour Movement Guidelines [1, 2] and/ or family healthy movement behaviours and/or involvement with organizations interested in children and youth in the context of the family, with stratification across movement behaviours (i.e., physical activity, sedentary behaviours, sleep) and attention to geography, gender and career-stage diversity. The Expert Panel first met on May 16-17, 2019 in Toronto, Canada. The objectives of this first meeting were to meet and network; explain the history and purpose of the ParticipACTION Report Card and how this Consensus Statement relates to the Report Card; present background efforts and research; brainstorm content/focus; and discuss the form, format, timelines and logistics of the Consensus Statement development. The Expert Panel was also invited to provide suggestions for additional panel members to fill any knowledge or expertise gaps. Four additional members were invited and all accepted invitations to be involved in the subsequent meeting and related project tasks.

The group met for a follow-up meeting in January 2324, 2020 in Toronto, Canada, where results of the reviews and custom analyses were presented, other research evidence was discussed, a glossary and a conceptual model were developed, initial communication and dissemination strategies were planned, and organization for a stakeholder consultation was initiated. In addition, a first draft of the Consensus Statement was created by the Expert Panel and finalized after the meeting through an iterative process to achieve consensus.

An online survey was developed and administered to solicit assessments and comments from stakeholders on the draft Consensus Statement. The survey was designed to seek assessments of the clarity and level of support for the various components of the Consensus Statement (title, summary, evidence, conceptual model, recommendations) separately. A copy of the survey is provided as Additional File Survey. Quantitative data were gathered from five-point rating scales that went from strongly disagree to strongly agree and qualitative data were gathered through open comment boxes for each component. The survey was disseminated through the networks of Expert Panel members. The survey was only live for 4 days because of time restrictions related to a set release date. The Steering Committee collated the responses and thematic analysis was undertaken to identify prominent or emerging themes to help better shape the wording, content and utility of the Consensus Statement. The Consensus Statement was revised accordingly. Finally, the revised Consensus Statement was circulated to the entire Expert Panel for final comment, revisions, and sign-off. The final Consensus Statement was translated into French and both the English and French versions went through a creative design process by ParticipACTION for inclusion in the 2020 ParticipACTION Report Card. A summary overview of the timelines and key components of the Consensus Statement is provided in Fig. 1.

\section{Results}

\section{Establishment of expert panel}

Twenty-one candidates were initially invited to join the Expert Panel, including two international delegates, and information was provided on the commitement required. Fourteen of the invitations were accepted. Reasons for invitation decline were either too many concurrent commitments $(n=4)$ or no response received $(n=4)$. One international delegate declined and the other did not respond. At the first Consensus Panel meeting four additional candidates were identified and invited to join. 
Strategic meeting to select topic (October 2018)

Identify and invite experts (March 2019)

Conduct literature reviews on family and physical activity, sedentary behaviour/screen time, and sleep (November 2018 - May 2019)

\section{Expert Panel Meeting \#1 (May 2019)}

Revise initial literature reviews (reviews \#1-3) and conduct reviews \#4-6 (June - November 2019)

Commission custom data analyses from Statistics Canada (November - December 2019)

Expert Panel Meeting \#2 (January 2020)

Draft Consensus Statement and conceptual model prepared (January - February 2020)

\section{Stakeholder Survey (February 2020)}

Expert Panel consensus achieved (February 2020)

Manuscript submitted for publication (February 2020)

Consensus Statement copy-edited, translated, layout and design (March - May 2020)

Report Card and Consensus Statement release (June 16, 2020)

Fig. 1 Overview of timelines and key components of the Consensus Statement development

Invitations were sent and all four accepted. The final Expert Panel composition included 17 experts. Two research staff (KB, MP) provided significant support to the Expert Panel.

An overview of the evidence obtained from the six reviews, analyses from Statistics Canada's Canadian Health Measures Survey, results of the stakeholder consultation, final conceptual model, presentation of final Consensus Statement, and release and evaluation plans are provided below.

\section{Family and children and Youth's movement Behaviours (reviews \#1-3)}

Inclusion and exclusion criteria for reviews \#1-3 are summarized in Additional File Table S1. Article titles and abstracts for each review were screened and categorized into themes. A summary of the search process, the findings organized by theme, and all references are provided in Additional Files Review \#1, Review \#2, and
Review \#3, respectively. Search details and key findings of the most frequently researched family characteristics related to physical activity (physical activity modelling, parental emotional support, sociodemographic factors, and parental beliefs, attitudes and knowledge), sedentary behaviour (parental behaviours, sociodemographic factors, and household practices) and sleep (household practices, sociodemographic factors, and family environment) are outlined in Table 2.

Family systems theory, correlates of parental support for child and youth movement Behaviours, and family-based interventions (reviews \#4-6)

Inclusion and exclusion criteria for reviews \#4-6 are summarized in Additional File Table S2. A summary of the search process for reviews 4-5, and all references can be found in Additional Files Review \#4, and Review \#5, respectively. The search process for review \#6 can be found in Additional File Figure S1 (all references for 
Table 2 Search details and key findings of reviews \#1-3

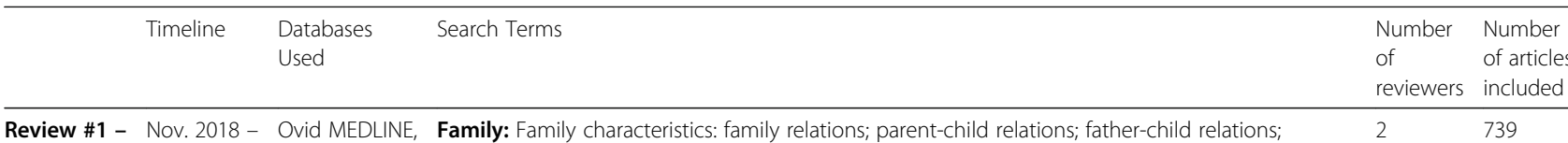

Physical Nov. 2019 Embase
activity

mother-child relations; parenting; parenting styles; parental behaviour; parents; fathers;

mothers; siblings; sibling relations; bother; sister; attitudes; perception; attitude to health;

health behaviours.

Physical activity: Physical activity; exercise; sport; physical exertion; aerobic; active transportation;

active neighbourhood

\section{Key findings Physical activity modelling $(\boldsymbol{n}=\mathbf{3 5 9})$ :}

- A review of reviews ( $k=18 ; 375$ quantitative studies) demonstrated that family behaviours, such as modelling or co-participation, had a stronger positive relationship with children's physical activity than more general family household practices and beliefs [81].

- Parental physical activity was positively associated with their children's physical activity levels $(k=10)$ [53].

- Longitudinal studies that followed families over a period of 5 years (from the time children were 5-6-year-olds to 10-12-year-olds) demonstrated that maternal physical activity [82], paternal reinforcement [82], and sibling co-participation [83] were positively associated with MVPA among pre-adolescent and adolescent boys and girls; however, only girls' MVPA was negatively associated with maternal sedentary behavior [83].

- Findings from a systematic review of cross-sectional studies $(k=10)$ demonstrated that both parents' modelling behaviours were positively associated with their children's (3-19years) physical activity behaviors [84].

- Parental modelling of active transportation was also important, such that it reduced the negative association between perceived safety and youth's active transport [85], which is a significant barrier for active transportation for children and adolescents [86-89].

Parental emotional support $(n=234)$ :

- Systematic reviews on children ([90] $k=3,[79] k=11)$ and adolescents $([90] k=4$, [91] $k=75$, [92] $k=52)$ found that familial and parental social support were consistently positively associated with increased physical activity in cross-sectional and longitudinal studies. For adolescent girls, this effect was slightly stronger when support came from the mother $(r=$.22) compared to support from both parents $(r=.19)$ [92]. When examining studies that included both genders, more consistent positive associations were found when support came from the entire family or from both parents rather than each family member separately (e.g., mother, father, siblings) [91].

- Mixed results were found when examining the relationship between parental encouragement/support and outdoor play in children, with studies showing either positive or null relationships $(k=11)$ [93].

Sociodemographic factors $(n=172)$ :

- Parental education and income, but not employment status, were associated with children's physical activity [93].

- A systematic review $(k=12)$ indicated that children of higher educated parents engaged in less outdoor play [93]. This result was most consistent when maternal education was high $(k=6)$ [93]. This finding is also supported by independent studies and other systematic reviews, whereby children of mothers with a graduate or professional degree were more likely to be inactive [94] and less likely to use active transportation $(k=9)$ [95].

- Association between household income and physical activity varied depending on the type of physical activity. For outdoor play, a systematic review $(k=5)$ showed that there was no association between household income and time spent in outdoor play [93].

- Findings from independent studies show that higher household income was positively associated with children's leisure physical activity [94] and engagement in sports [96, 97]; however, evidence from a systematic review $(k=21)$ showed that higher household income was negatively associated with use of active transportation [95].

Parental beliefs, attitudes, and knowledge $(n=134)$ :

- Parental beliefs about safety of physical activity-related activities and their neighbourhood were shown to be important for outdoor play [88, 98], leisure [86, 99], and organized physical activity [99].

- Parental attitudes toward physical activity have been shown to be associated with youth's physical activity; children of parents who believe physical activity is important are more likely to engage in organized $[99,100]$ and leisure $[99,101]$ physical activities.

- Parental modelling [102-104] and child stimulation of healthy dietary intake [104] were positively associated with children and youth physical activity levels.

Review \#2 - Nov. 2018 - Ovid MEDLINE, Family: Same search terms outlined in review \#1 applications; social media; Facebook; YouTube; Twitter; Snapchat; Instagram; Pinterest; screen viewing; screen-time.

Key Findings Parental behaviours $(n=104)$

- Substantial evidence showed that parents' sedentary behaviour and screen-time were positive correlates of children's sedentary behaviour and screen-time [105-119].

- Studies that specifically examined mothers' screen-based behaviours showed a positive correlation between mother and child's screen-time $[108,120,121]$

- Some evidence showed that co-viewing with parents was associated with increased screen-time in children [121, 122].

Sociodemographic factors $(n=92)$

- Parental education specifically and socioeconomic status more generally were negatively associated with sedentary behaviour and screen-time [123-134].

- Children and youth from families with higher socioeconomic status, but living in low- and middle-income countries, reported higher screen-time use than those from families with lower socioeconomic status [135].

- Mixed findings regarding how the presence, number, or type (younger vs., older) of sibling are associated with children's sedentary behaviour and/or screen-time [121, 136-138].

\section{Household practices $(n=84)$}

- Children who lived in a family with screen-time restrictions spent less time engaged in screen-based behaviours [126, 133, 139-149].

- Electronics in children and youth's bedrooms were associated with increased time spent in screen viewing [110, 111, 134, 150-156].

- Number of electronics in the household was a positive predictor of screen viewing $[144,157]$.

- Eating meals in front of the TV was linked with greater sedentary behaviour and screen viewing [134, 144, 157-159]. 
Table 2 Search details and key findings of reviews \#1-3 (Continued)

\begin{tabular}{|c|c|c|c|c|c|}
\hline & Timeline & & Search Terms & & $\begin{array}{l}\text { umber } \\
\text { articles } \\
\text { cluded }\end{array}$ \\
\hline & & & $\begin{array}{l}\text { Family: Same search terms outlined in review \#1 } \\
\text { Sleep: Sleep duration; sleep quality; Sleep timing; sleep routine; sleep hygiene; } \\
\text { sleep habits; sleep patterns; sleep efficiency; sleep behaviour; sleep interruption; sleep schedule. }\end{array}$ & 2 & 189 \\
\hline$y$ Findings & \multicolumn{5}{|c|}{ 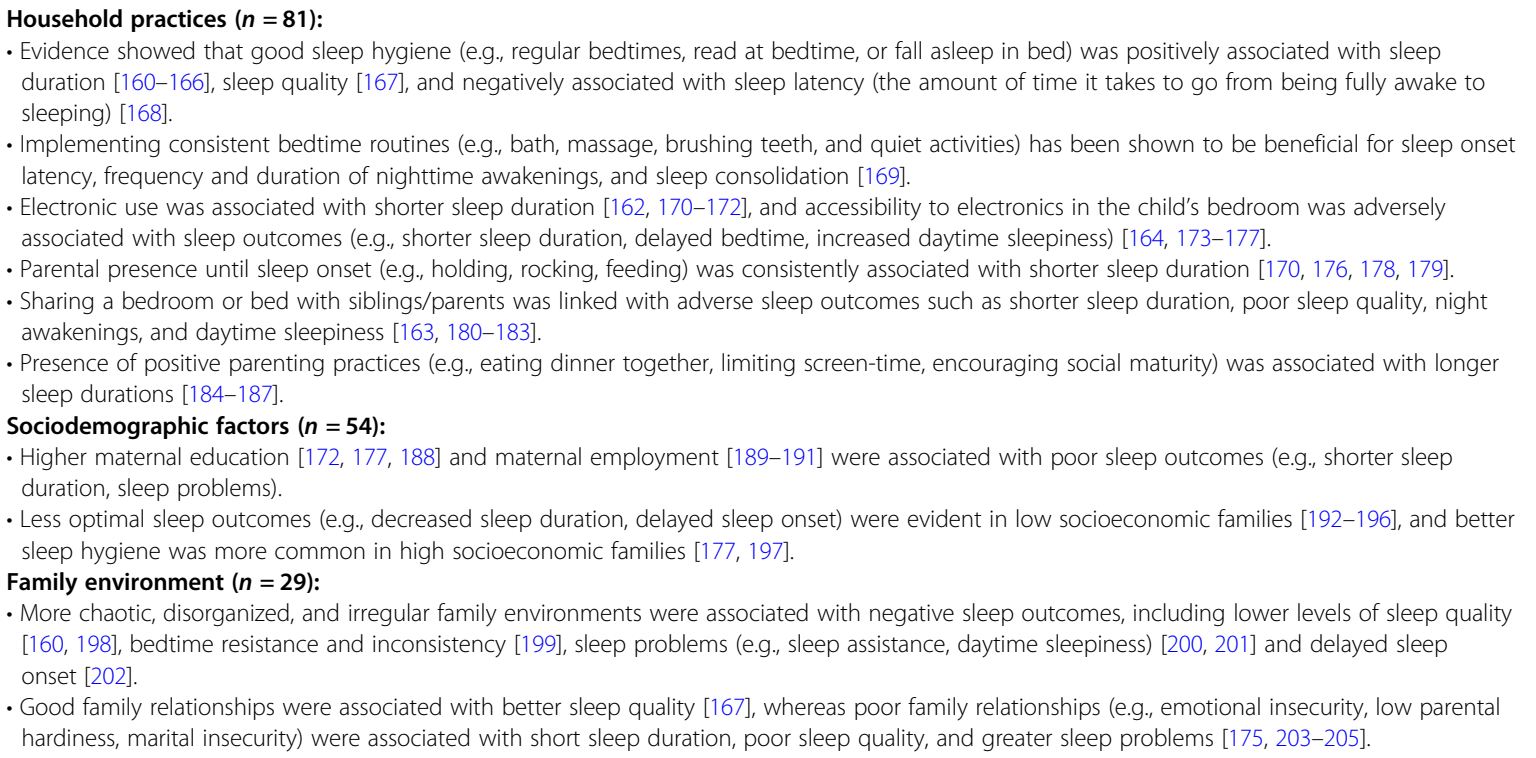 } \\
\hline
\end{tabular}

review \#6 are cited directly in the manuscript). Key findings are highlighted in Table 3. Review \#4 highlights the dynamic and fluid nature of the family system. While family systems have been incorporated into many schematics applied to child movement behaviours, the evaluation of these family systems approaches is scarce in the empirical literature. Review \#5 found few sociodemographic correlates of parental support for movement behaviours. Almost all of this research has been conducted on physical activity and not sedentary and sleep behaviours. Age was negatively associated with support. There is evidence that parenting cognitions about support (attitudes, perceived control, intentions) are key correlates of child and youth physical activity, while planning to support one's child is important for physical activity and sleep. Finally, review \#6 showed that considerable family intervention research is accumulating for child and youth physical activity promotion, followed by family involvement in screen-time interventions and less research on family involvement in child and youth sleep. Physical activity research has noted general effectiveness of family interventions, while the efficacy of family-based screentime interventions is less conclusive and the efficacy of family-based sleep interventions unknown. There are few moderators that have been identified for these interventions, but merely providing educational material for families may be ineffective in changing child and youth physical activity; instead, the current evidence shows that implementing behavioural approaches with families, including planning and setting goals, may be successful.

\section{Evidence from the Canadian health measures survey (CHMS)}

The results from the custom CHMS accelerometer analyses are presented below. In essence they show no significant differences in daily MVPA for boys or girls, of any age, based on number of siblings in the household. One exception is that for boys 12-17 years of age, having siblings had a positive association with physical activity. No differences in daily MVPA in 5-to-17 year-old children and youth according to a single- versus twoparent household structure; however, for 3-to-4 yearolds there is an effect whereby those living in households with two parents are more active than those living in households with one parent. There were no significant differences in the proportion of children aged 3 to 11 years meeting the daily MVPA recommendation of $\geq 60 \mathrm{~min}$ according to number of siblings in the household or single- versus two-parent household.

CHMS data on self- or parental-reported movement behaviours were also available for active transportation, recreational physical activity, occupational/ household physical activity, screen-time and sleep duration by number of siblings in the household and by single- versus two-parent household. For children 
Table 3 Search details and key findings of reviews \#4-6

\begin{tabular}{|c|c|c|c|c|c|}
\hline & Timeline & Databases Used & Search Terms & $\begin{array}{l}\text { Number of } \\
\text { reviewers }\end{array}$ & $\begin{array}{l}\text { Number of } \\
\text { articles included }\end{array}$ \\
\hline $\begin{array}{l}\text { Review \#4 - Family systems } \\
\text { approaches applied to } \\
\text { understand } 24-\mathrm{h} \text { movement } \\
\text { behaviours among } \\
\text { children and youth }\end{array}$ & $\begin{array}{l}\text { Sept. - } \\
\text { Nov. } 2019\end{array}$ & $\begin{array}{l}\text { Academic search premier, CINAHL } \\
\text { Complete, Cochrane Central } \\
\text { Register of Controlled Trials, Health } \\
\text { Source: Nursing/Academic edition, } \\
\text { Humanities and Social Sciences } \\
\text { Index (H.W. Wilson), MEDLINE with } \\
\text { Full text, PsychARTICLES, and } \\
\text { PsycINFO }\end{array}$ & $\begin{array}{l}\text { Family systems theory; family-based } \\
\text { interventions; childhood obesity; } \\
\text { 24-h movement behaviors; family } \\
\text { behaviour change; child behaviour } \\
\text { change; family and child physical } \\
\text { activity, sedentary and sleep behav- } \\
\text { iours; Family Ecological Model; fam- } \\
\text { ily characteristics; family relations; } \\
\text { parent-child relations; father-child } \\
\text { relations; mother-child relations; } \\
\text { parenting; parenting styles; parental } \\
\text { behaviour; parents; fathers; mothers; } \\
\text { siblings; sibling relations; bother; sis- } \\
\text { ter; attitudes; perception; attitude to } \\
\text { health; health behaviours. }\end{array}$ & 2 & 20 \\
\hline
\end{tabular}

Origin and development of family systems theory:

- Family systems theory is the primary theoretical approach to understanding and intervening upon family behaviour [206].

The approach has considerable overlap with Attachment Theory from developmental psychology [207] and highlights that the family is in a constant cycle of interactions with inherent evolution and change. Recurring challenges, reorganization, and changes are inevitable parts of the family life cycle that must be considered $[62,63]$. Interventions should likely target the family unit rather than the child in isolation.

- Barnhill [208] advanced the Family Systems Theory by specifying eight dimensions: individuation vs. enmeshment, mutuality vs. isolation, flexibility vs. rigidity, stability vs. disorganization, clear vs. unclear/distorted perception, clear vs. unclear/distorted communication, role reciprocity vs. unclear roles of role conflict and clear vs. diffuse or breached generational boundaries. These eight dimensions of healthy family functioning can be grouped into four mutually causal constructs that include identity processes, change, information processing, and role structuring.

- Bronfenbrenner [209] aextended family systems to a larger environment and proposed three systems that impact child development: mesosystems, exosystems, and chronosystems. Mesosystems incorporate the developmental processes that occur outside of the family home, such as experiences at school. Exosystems include parents' social networks, the workplace, and friend circles. The chronosystem describes life transitions. Bronfenbrenner highlights that these contexts do not operate independently of one another and instead interact with each other.

Family systems theory adapted for health behaviour changes:

- Davison and colleagues [210] presented the revised family systems ecological model, which incorporates factors that affect parenting cognitions and behaviours such as intra-familial (educational and cultural) backgrounds in addition to community factors (social connectedness to neighbours and friends). The model suggests that parenting for child health behaviour includes: i) knowledge and beliefs about health behaviour; ii) modelling of health behaviours; iii) shaping of child behaviour through rewards and punishments; and, iv) provisions for the child to engage in the health behaviour.

- Myoungock and Whittemore [211] proposed the family management style framework for childhood obesity interventions. It focuses on family functioning and parental perspectives associated with the management of children's health behaviours.

- Kitzman-Ulrich and colleagues [212] proposed a Family Systems Theory framework for evaluating family-level variables and positive (authoritative) parenting styles that lead to improvements in youth health behaviours (physical activity, dietary and weight-loss behaviours).

- Nowicka and Flodmark [213] presented a family therapy model for treating childhood obesity known as Standardized Obesity Family Therapy (SOFT). The SOFT model integrates Family Systems Theory and elements used in focused solution development such as creating expectations for change, establishing goals for therapy and defining potential solutions.

- The Levels of Interacting Family Environmental Subsystems (LIFES) framework incorporates theoretical concepts from ecological systems and Family Systems Theory [214], highlighting that child health behaviours are influenced by both child factors and factors existing within the family (i.e., parents' behaviours, parenting practices and family functioning).

Studies that have tested family systems approaches with interventions $(n=2)$ :

- Both studies applied the SOFT model [213] to examine integrating Family Systems Theory and solution-focused theory (i.e., focusing on solutions, preferred future and goals as opposed to the problem and its cause) into family therapy sessions for adolescents and their families.

- This treatment model focused $n$ engaging the whole family in the obesity treatment process with an emphasis on encouraging physical activity ( $60 \mathrm{~min}$ per day) and reducing sedentary screen-time (less than $2 \mathrm{~h}$ per day). Both interventions were effective in decreasing child body mass index in comparison to control conditions; unfortunately, no behavioural outcomes were assessed in these trials so the complete understanding of the effectiveness of the intervention is limited [215, 216].

Timeline Databases Used

Sept. - $\quad$ Academic search premier, CINAHL Nov. 2019 Complete, Cochrane Central
Search Terms

Parent; caregiver; mother; father; parental support; parenting
Number of Number of reviewers articles included

3 25 (22 unique datasets) 
Table 3 Search details and key findings of reviews \#4-6 (Continued)

\begin{tabular}{|c|c|c|c|c|c|}
\hline & Timeline & Databases Used & Search Terms & $\begin{array}{l}\text { Number of } \\
\text { reviewers }\end{array}$ & $\begin{array}{l}\text { Number of } \\
\text { articles included }\end{array}$ \\
\hline $\begin{array}{l}\text { and youth 24-h movement } \\
\text { behaviours }^{\mathrm{a}}\end{array}$ & & $\begin{array}{l}\text { Register of Controlled Trials, Health } \\
\text { Source: Nursing/Academic edition, } \\
\text { Humanities and Social Sciences } \\
\text { Index (H.W. Wilson), MEDLINE with } \\
\text { Full text, PsychARTICLES, PsycINFO, } \\
\text { SPORTDiscuss, and ScienceDirect }\end{array}$ & $\begin{array}{l}\text { practices; parenting strategies; } \\
\text { parenting behaviours; parental } \\
\text { correlates; child; adolescent; } \\
\text { physical activity; exercise; sport; } \\
\text { physical exertion; aerobic; active } \\
\text { transportation; active commute; } \\
\text { park; outdoor; outdoor play; active } \\
\text { lifestyle; active neighbourhood. } \\
\text { Prospero\# CRD42020154439 }\end{array}$ & & \\
\hline
\end{tabular}

Key Findings

Review \#6 Family-based interventions on children and youth 24-h movement behaviours

Key Findings

\section{Composition of studies and characteristics}

- Sixteen studies focused on physical activity support (76\%), with two studies focused on sleep support [54, 217] and four on sedentary behaviour or screen-time restriction [14, 218-220]. The majority of the studies used a crosssectional design, and the targets of the support focused on both children and youth; only $27 \%$ focused on a single age group (i.e., children or adolescents).

- Overall, parental support measurement was extremely varied, with most studies employing different instruments However, the assessment of frequency of encouragement, logistical support, and co-participation activity were common elements across most of the measures and all measures reported generally sound indicators of reliability.

\section{Correlates of parental support of child and youth physical activity}

- Among potential demographic correlates of physical activity, only child age showed a reliable negative association (median $r=-$.13) $[59,218,221-228]$, suggesting that older children and youth received less support than younger children and youth.

- All social-cognitive factors assessed (attitudes, perceived control) were significant correlates of parental support in the medium effect size range [229]. Intention and planning to support were correlated with support behaviours in the large effect size range [229].

- Parenting style, in the form of authoritative parenting, had mixed results as a correlate of support for child/youth physical activity $[225,230]$

- Neighbourhood safety [225] was a correlate of parental support in the small effect size range (median $r=.16$ ) [229].

\section{Correlates of parental restriction of child and youth sedentary behaviour}

- Sedentary behaviour restriction studies included only two correlates. Child body mass index and parent gender had no association with sedentary behaviour measured as screen-time) restriction [219, 220].

\section{Correlates of parental support of child and youth sleep}

- Studies on parental support of child and youth sleep found child age had a negative relationship with sleep support $[54,219]$. Planning was the only cognitive and behavioural construct present in current studies and it showed a medium sized association $(r=0.24-0.50)$ with sleep support $[54,217,218]$.

\section{Timeline Databases Used}

Sept. - $\quad$ Academic search premier, CINAHL

Nov. 2019 Complete, Cochrane Central Register of Controlled Trials, Health Source: Nursing/Academic edition, Humanities and Social Sciences Index (H.W. Wilson), MEDLINE with Full text, PsychARTICLES, PsycINFO, SPORTDiscuss, and ScienceDirect

\section{Search Terms}

Family-based; family mediators; family interventions; family moderators; behavior change strategies; children; youth; sleep; bedtime; sports; exercise; physical activity; sedentary lifestyle; sedentary behaviour; inactivity; physical inactivity; sitting; laying; TV; TV viewing; video games; Internet; computer; screen; smartphone; iPad; apps; mobile applications; social media; Facebook; YouTube; Twitter; Snapchat; Instagram; Pinterest; screen viewing; screentime.
Composition of studies and characteristics

- Eleven review articles met the inclusion criteria [49-51, 231-238]. Two-hundred and fifty studies (not independent) from the 11 review articles targeted child and adolescent physical activity behaviour. Four review articles incorporated 83 studies (not independent) that targeted screen-time and/or sedentary behaviours in addition to physical activity [49, 51, 234, 235]. Only one review that included 24 studies addressed child sleep behaviours [49], but this did not include the efficacy of these interventions.

- The majority of reviews included studies published between 1980 and 2015. All reviews targeted families with school-aged children (5-12 years old) and eight of these also included adolescents (12-18 years old). Overall, the reviews targeted diverse samples whereby four reviews included families of low socioeconomic status [49, 231, 234, 235], and six reviews targeted ethnic minority populations [49, 50, 231, 232, 235, 238]. Four reviews included randomized controlled or quasi-experimental trials only $[49-51,231]$ and the other reviews also incorporated noncontrolled trials, pilot or feasibility studies, and prospective cohort studies [232-235, 237, 238]. 
Table 3 Search details and key findings of reviews \#4-6 (Continued)

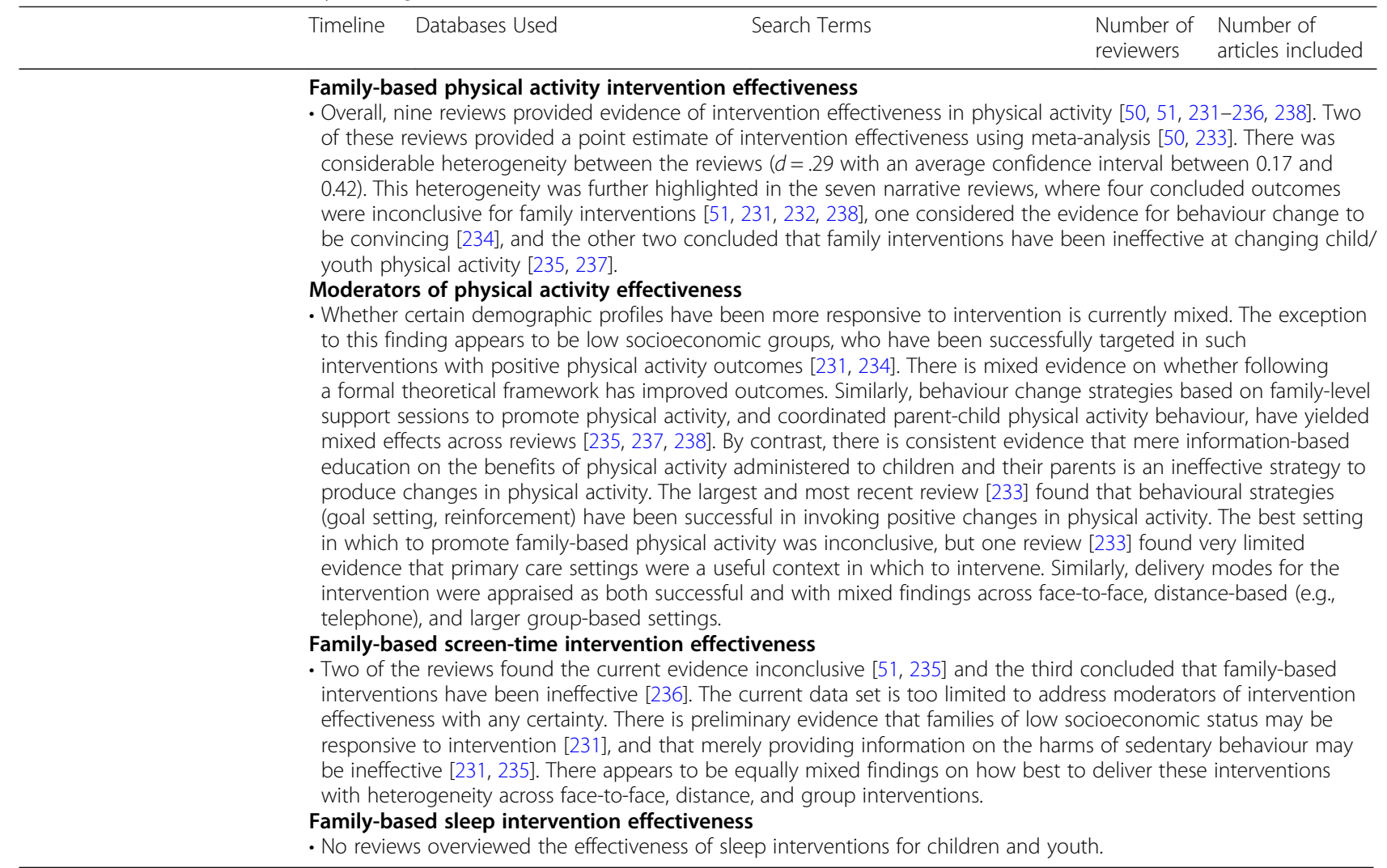

${ }^{a}$ Full details on the physical activity portion of this review can be found in Rhodes, R.E., Perdew, M. \& Malli, S. (in press). Correlates of Parental Support of Child and Youth Physical Activity: A Systematic Review. International Journal of Behavioral Medicine

aged 3 to 4 years and for youth aged 12 to 17 years, there were no significant differences for any variables by number of siblings or parents. For children aged 5 to 11 years, the following significant differences were observed:

- Girls with no siblings or one sibling participated in more organized sports, lessons, and leagues compared to girls with two or more siblings;

- Boys with two or more siblings participated in more unstructured play outside of school compared to boys with one sibling or less;

- Girls in two-parent households participated in more organized sports, lessons, and leagues compared to girls in one-parent households;

- Girls and boys from two-parent households had less screen-time compared to single-parent households; and,

- Boys from two-parent households had more sleep compared to boys from single parent households.

In addition to the custom analyses described above, recently published findings from the CHMS examined parent and child sedentary behaviour and physical activity in early childhood [239]. This study found that higher parental screen-time, sedentary time, light physical activity and MVPA were significantly associated with higher screen-time, sedentary time, light physical activity, and MVPA, respectively, of their children in this large representative sample of Canadian 3-5-year-olds. The strength of relationships did not differ between weekdays and weekend days, sons and daughters or mothers and fathers [239].

Recently published findings from the same family parent-child dyad file explored parent-child associations for physical activity and screen-time [112]. These findings demonstrated the parents' MVPA (parental role modelling) was associated with that of the child, with each additional $20 \mathrm{~min}$ of parental MVPA being associated with an extra 5 min of child MVPA [112]. Parents' sedentary time was also associated with daughters' sedentary time on weekends, and sons' after school. Supporting children to be active through enrolment in organized sports, leagues or lessons was also positively associated with a child's MVPA. Parental role modelling and supporting children to be active had independent 
effects. This is important because in some cases, parental modelling may be an insufficient influence on the physical activity of their children because parental participation in physical activity by itself does not remove potential barriers to their child being active (e.g., providing transportation to an activity, learning new skills).

Custom dyad analyses using accelerometer data generally showed significant associations for MVPA and sedentary behaviour among mother-daughter dyads, and for MVPA among father-son dyads. Custom dyad analyses on measures of fitness also show significant associations between parents and children for cardiorespiratory fitness, muscular strength, and flexibility. Correlation analyses indicate that the relationship is stronger in:

- Father-daughter pairs for cardiorespiratory fitness and muscular strength;

- Father-son pairs for muscular strength and flexibility; and.

- Mother-son pairs for muscular strength and flexibility.

Collectively the results for the CHMS show that while number of siblings and single- versus two-parent households are not generally associated with 24-h movement behaviours, the behaviours (physical activity and screentime) and characteritsics (physical fitness) of parents are associated with the behaviours and characteristics of their children. These findings align with those found in the various reviews described above where parental role modelling was consistently found to be an important correlate of children's 24-h movement behaviours.

Stakeholder survey results and subsequent modifications Sixty-seven stakeholders responded to the survey in the 4 days it was live. The sample consisted of a wide mix of sectors, yet a particularly large concentration of researchers (6 nongovernment organizations, 1 family support, 10 education, 1 recreation, 2 childcare, 2 healthcare, 5 public health, 32 research, 5 government, 3 other). Further, stakeholders were from Alberta $(n=9)$, British Columbia $(n=18)$, Nunavut $(\mathrm{n}=1)$, Ontario $(n=$ $18)$, Prince Edward Island $(n=1)$, Quebec $(n=4)$, Saskatchewan $(n=1)$, and outside of Canada $(n=18)$.

Overall, stakeholders agreed with the Consensus Statement. Specifically, $78 \%$ of the sample thought the title was clearly stated, $96 \%$ indicated the summary was clearly stated, $82 \%$ of the sample reported they would use the Consensus Statement, 99\% of the sample thought the evidence for the statement was clearly stated, $76 \%$ indicated the conceptual model was clearly presented, and $95 \%$ of the sample reported the recommendations were clearly stated. Overall, $88 \%$ of the sample reported that the Consensus Statement would be (very to moderately) important to their work, while only one stakeholder reported that it would not be important.

The survey respondents were engaged and provided many comments and suggestions. Most comments were minor editorial suggestions (which were made) or compliments. As noted above, the level of agreement was very high. Nevertheless, a few clusters of suggestions emerged, albeit from a small minority of respondents. First, there was some concern about the title - that it was unclear $(n=6)$ or confusing $(n=3)$. Changes were made to address these concerns. Second, there were several small suggestions about the conceptual model, and these were also incorporated in revisions. Third, four respondents commented that there was too much responsibility placed on the family, however this was before they reached the portion of the survey that dealt with the other sources of influence on the family (e.g., schools, community, health care, government). Nevertheless, additional clarification was added to improve clarity that although the Consensus Statement is focussed on the role of the family, the Statement also speaks to the importance of those who influence and can support families. Finally, two respondents suggested that a review be completed to ensure inclusive language, particularly with respect to children with a disability. This was also completed and revisions made accordingly.

\section{Final Consensus Statement, conceptual model, release, and evaluation plans}

After meeting to discuss the findings of the six reviews and the custom analyses, performing multiple rounds of reviews and revisions, and incorporation of feedback through the stakeholder survey, the Expert Panel reached consensus on the final Consensus Statement on the Role of the Family in the Physical Activity, Sedentary, and Sleep Behaviours of Children and Youth. The Consensus Statement itself is a concise, public-facing, authoritative consolidation of research evidence. The statement includes brief background text, summary of the process, key summary points and sources of the aggregated evidence, a conceptual model consolidating the scope of the findings, followed by concise recommendations to anticipated audiences (e.g., family members, educators, health professionals, government, researchers). The Consensus Statement concludes with key support resources, acknowledgements and references. It was designed to be a foundation of credible evidence from which programs, strategies, campaigns, policies and practices can be initiated and supported. The Consensus Statement as a knowledge product within the 2020 ParticipACTION Report Card on Physical Activity for Children and Youth [85] was released on June 16, 2020. The final Consensus Statement can be found in Fig. 2 (see also: https://participaction.com/consensus-statement). 

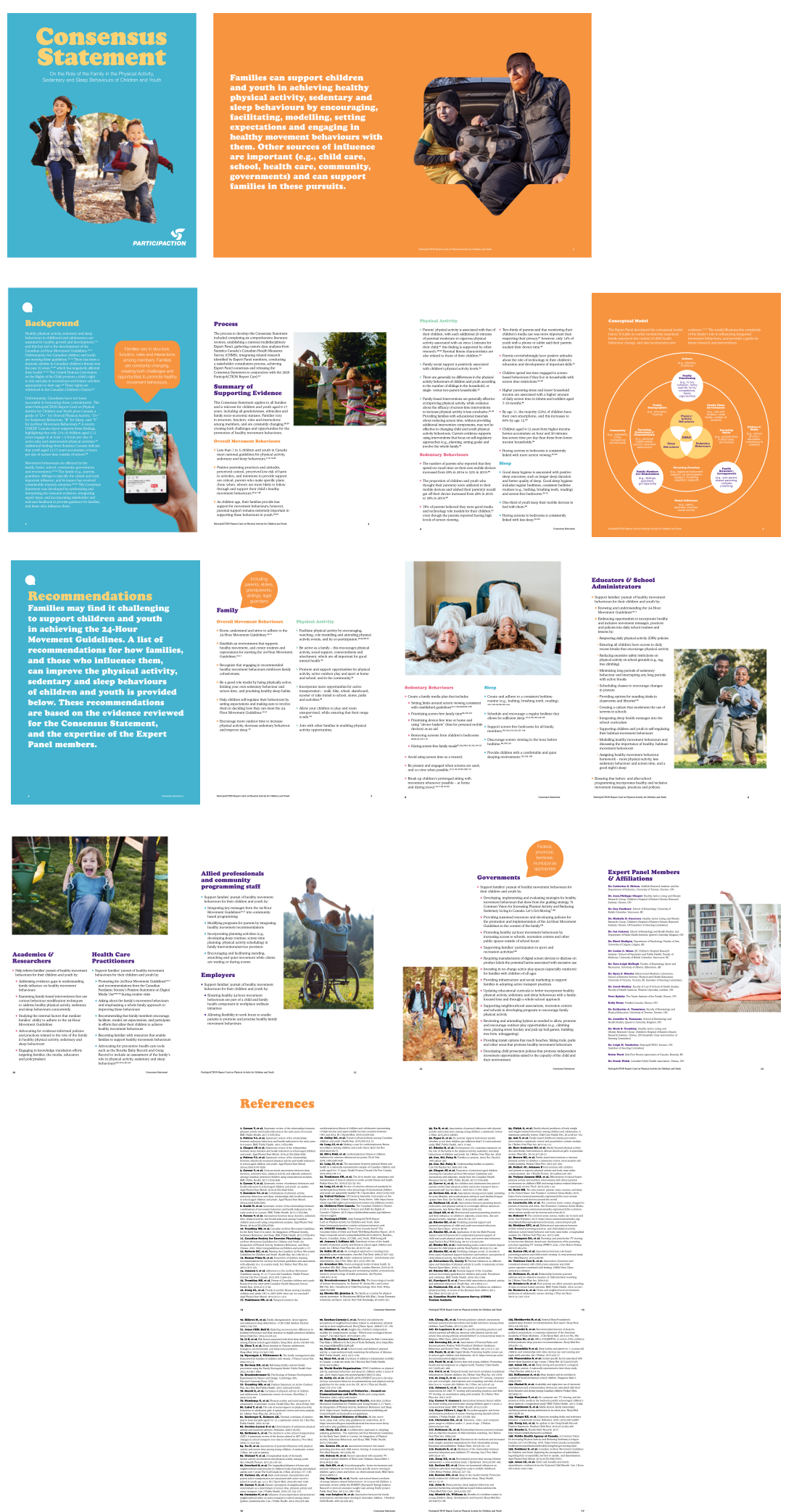

Fig. 2 Consensus Statement on the Role of the Family in the Physical Activity, Sedentary, and Sleep Behaviours of Children and Youth. Document can be found at: https://participaction.com/consensus-statement 
The Consensus Statement is also available in French at https://www.participaction.com/fr-ca/ressources/bul-

letin-de-participaction.

To maximize the impact of the Consensus Statement, a public relations and dissemination plan was developed and led by ParticipACTION. The release of the Consensus Statement benefited greatly from the proactive distribution, public relations and media strategy prepared to maximize and optimize the reach and impact of the release of the ParticipACTION Report Card. Through the Report Card, the Consensus Statement reached relevant stakeholders (approximately 50,000 educators, health professionals, government, media, and researchers) across Canada. The general public (expectation of more than 300,000 Canadians) were reached directly through public-facing communications and social channels and indirectly through the media.

To ensure targeted reach to the specific audiences highlighted in the Consensus Statement, it was further shared by the networks of the Expert Panel members and their affiliated organizations. Specific findings were shared via ParticipACTION's and other partnering individuals'/organizations' social media channels (e.g., Twitter, Facebook, Instagram, blogs). Press releases and communications with partnering organizations' networks also took place on the day of release. An evaluation of the Consensus Statement release will occur as part of the larger, more comprehensive Report Card evaluation plan, including tracking of distribution, media impressions, hits and quality, website traffic and site visits, social media reach, and engagement among users. Surveys with Report Card users and debrief meetings with ParticipACTION's strategic partners and Expert Panel members will provide further important insights.

\section{Discussion}

A comprehensive process was initiated in Canada to develop and release a Consensus Statement on the Role of the Family in the Physical Activity, Sedentary, and Sleep Behaviours of Children and Youth to consolidate related evidence, highlight key considerations, and provide recommendations to families and other related networks on how to support regular healthy movement behaviours as outlined by the Canadian 24-Hour Movement Guidelines for Children and Youth [1, 2]. Triangulated evidence was obtained from six reviews, analyses from Statistics Canada's CHMS, and feedback and insights by Expert Panel members and those who responded to the stakeholder survey. This process culminated in the Consensus Statement (Fig. 2), the development of a conceptual model, a discussion of the key take-away messages, and concluded with the identification of critical gaps in current knowledge that form recommendations for future research.
An explanation and substantiation for the final content of the Consensus Statement is provided below. First, the summary statement deliberately situates the family as the proximal micro-system of child influence, following the work of Bronfenbrenner [209] that was outlined in the family systems review (review \#4). It subsequently provides several descriptors of how a family may support child and youth movement behaviours to acknowledge the complex assortment of behaviours and practices found within the reviews on the correlates of parental support, and family characteristics and children and youth's physical activity, sedentary, and sleep behaviours. This information was directly informed by the review of family support correlates (review \#5) and indirectly based on reviews \#1-3 and review \#6.

The Background section of the Consensus Statement highlights the importance of child and youth movement behaviours, noted from past evidence that formed the Canadian 24-Hour Movement Guidelines for Children and Youth $[1,2]$, augmented by contemporary epidemiological evidence from our custom analyses from Statistics Canada, and supported by the United Nations Convention on the Rights of the Child [240] and the Canadian Children's Charter [241]. Given that movement behaviours are socioecological in scope [242], the background section concludes with a more fulsome statement about the multiple sources of influence that shape child and youth movement behaviours to inform readers that family is but one important system among these core elements, as evidenced from all of our reviews, the stakeholder survey feedback, and input from the Expert Panel.

The process that was used to achieve the Consensus Statement, noted in the Methods section of this paper, is summarized for readers to provide the background for how we arrived at our conclusions and recommendations. This included the funding sources, reviews undertaken, the formation of the national Expert Panel, custom analyses, and stakeholder consultation process and tied release to the 2020 ParticipACTION Report Card. Finally, we note that the applicability of the Consensus Statement is meant to be broad and inclusive of children and youth of all gender/sex, ethnicities, and family socioeconomic status.

The Consensus Statement follows with a series of key evidence statements to stakeholders that broadly outline the importance of movement behaviours to child and youth health, and the role of the family, based on the evidence acquired through the process used to generate the statement. These points were not meant to be exhaustive; rather, they represent highlights of key takeaways from the reviews, analyses, and discussions of Expert Panel members that have the most evidence at present and also resonate with the Consensus Statement 
and recommendations to ensure cohesiveness of the document. These include:

- parental emotional support, physical activity modelling, parental knowledge/beliefs about physical activity, and various sociodemographic factors are related to children's physical activity;

- parental modelling (physical activity and screentime) and family expectations (rules) were important for limiting children and youth's sedentary behaviour and screen-time;

- healthy expectations such as setting bedtime routines and having device-free bedrooms and good family functioning were important for helping children and youth acquire sufficient sleep; and,

- the entire family system is an important source of influence and subsequent promotion of healthy child and youth behaviours.

To relieve the word-heavy approach in the Consensus Statement and add visual representation of the findings from our process, the Expert Panel developed a conceptual diagram that highlights how we situate family influence on child and youth movement behaviours (Fig. 3). The figure was developed from the findings of all six reviews, the CHMS analyses, as well as input from the Expert Panel, and the stakeholder survey feedback.
Through a Venn diagram, the illustration portrays physical activity, sedentary, and sleep behaviours as integrated, commensurate with the Canadian 24-Hour Movement Guidelines for Children and Youth [1], but also recognizing their unique variation that may require targeted attention. A series of concentric circles were used to situate family as a proximal source of influence, while allowing readers to quickly see that there are many sources and settings that influence child and youth movement behaviours beyond the family [209, 243, 244]. We positioned the types of influence (i.e., parenting practices, parent preferences and characteristics, parenting styles) as immediate to child and youth movement behaviours to denote the key mediators of action and then highlight core family systems constructs (i.e., family functioning, family structure, family members as stakeholders) as the likely sources of those types of influence. Finally, we acknowledge key additional influences (i.e., family demographics, community, policies and media, additional social influences) on family and subsequent child and youth movement behaviours in the outer concentric circle.

In the Consensus Statement, we dedicated considerable space to recommendations, subdivided by key stakeholders, because the ultimate purpose of the Consensus Statement is to act as an actionable document. Consideration was given to each potential group of stakeholders

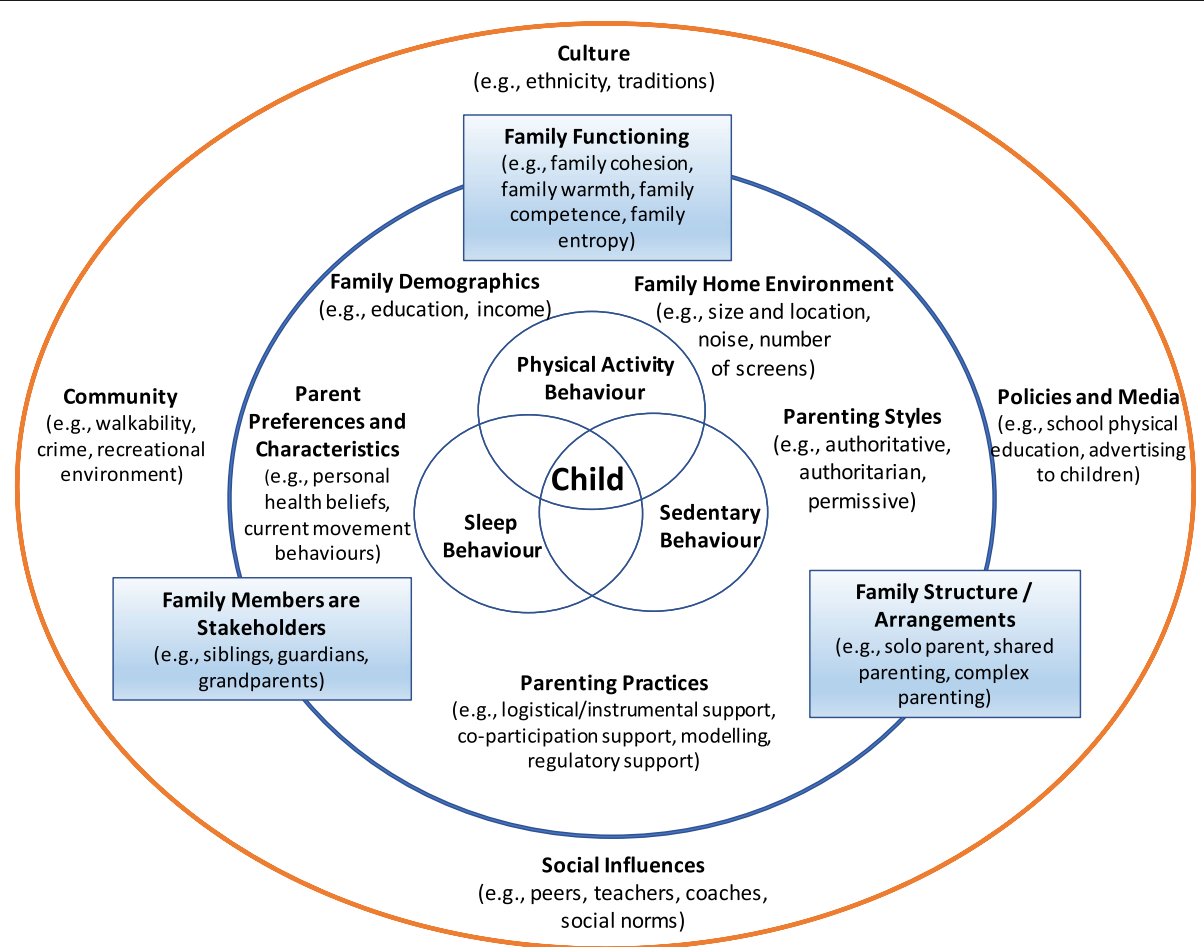

Fig. 3 Conceptual model illustrating the relationships linking family and the physical activity, sedentary and sleep behaviours of children and youth, within a socioecological context 
and recommendations were themed accordingly. These included family - broadly defined to incorporate the many structures and roles that encompass a family [245], educators, researchers, practitioners, service providers, and governments at all levels. Recommendations were evidence-based from the results of our reviews as well as discussion points among the Expert Panel and recommendations generated through the stakeholder survey. For example, for family, these included recommendations to model, facilitate, and encourage their children and youth to meet the Canadian 24-Hour Movement Guidelines [1] by creating routines, plans, priorities, and expectations. Co-activities were encouraged for physical activity and screen-time to monitor and socialize as a family. For all movement behaviours, we included a series of specific tactics that may be useful for families to assist in limiting screen viewing hours of children and youth based on the literature reviewed in our process of generating the Consensus Statement. A similar process for generating recommendations was followed for all other stakeholders.

The Consensus Statement was created to inform and activate stakeholders to promote healthy child and youth movement behaviours. In doing so, we were mindful of its length and the important balance between building an evidence-based document and an authoritative and thorough resource. Thus, to conclude the Consensus Statement we included a series of additional resource links and references for end-users to continue learning about the evidence used to build the document and other excellent sources of information related to the themes raised within the statement.

While the process we undertook to develop the Consensus Statement identified considerable evidence to substantiate the statement, it also demonstrated there are several aspects of family and child and youth movement behaviours where there are still gaps in the research literature. For example, a very recent systematic review ( $n=23$ studies, 1982-2019) which examined whether interventions with a parent/other adult caregiver component resulted in children being more physically active, reported little to no impact on children's activity levels [246]. The most commonly reported intervention techniques were those aimed at shaping participants' knowledge, such as providing instruction about how to perform a behaviour. However, the majority of included papers were of low or very low quality, and therefore, caution should be taken when interpreting the findings (uncertainty of the results). Accordingly, research priorities are noted below:

- Despite existing adaptations of Family Systems Theory for child and youth health behaviour in the form of schematics, only two trials $[215,216]$ focused on child physical activity and screen-time reduction, have been conducted. Clearly, this represents a paucity of research utilizing family systems to change behaviours of the 24-Hour Movement Guidelines for Children and Youth [1,2].

- While parental practices in relation to child and youth movement behaviours has been linked to subsequent child and youth behaviour, current research highlights the paucity in our understanding of parental practices related to sleep and restriction of sedentary behaviour. More research on the antecedents of parental practices is needed.

- Parental practices and support of all movement behaviours would be better understood with a greater focus on social (e.g., norms, network, support) and environmental (e.g., home, community, policy) correlates of support in conjunction with individual factors. Such evidence is required.

- Almost all of the current evidence-base on family support of child movement behaviours is focused on parents, and much of this is exclusive to mothers. Family functioning (e.g., cohesion, entropy, chaos), structural arrangement supports (e.g., divorced shared parenting, single parenting) and overall family stakeholders (e.g., fathers, extended family, siblings) would assist in understanding the relative contributions of family influence.

- Research of family-based interventions for physical activity has improved over the last decade, yet family interventions on child and youth sleep and sedentary behaviour are limited. Primary research focussed on interventions to improve sedentary behaviours and sleep are still required in order to generate evidencebased recommendations.

- Interventions targeting a single movement behaviour are helpful, but we also recommend an examination of overflow effects on other non-targeted movement behaviours (e.g., does a family physical activity intervention result in better sleep practices?).

- Family intervention comparisons between integrated 24-h healthy movement behaviour approaches compared to isolated individual movement behaviour approaches will be a helpful future research direction to determine the best practice of (e.g., sequencing) behaviour change.

- Determining the best knowledge translation and mobilization techniques to increase stakeholder's awareness, knowledge, understanding, and implementation of recommended amounts of physical activity, sedentary behaviour, screen-time and sleep is needed.

This initiative was undertaken by a large interdisciplinary team of researchers, clinicians, policy experts, public 
health professionals, and front-line family service providers. Though we sought international representation for the Expert Panel, our final composition lacked an international perspective. The undertaking of multiple literature reviews and custom national data analyses combined with ongoing expert consultation, was a significant strength of this project. The findings of this work have the potential to inform future contributions to the child health literature, care, and practice. With the pragmatic use of literature searches and scoping reviews rather than systematic reviews being carried out, data quality, full synthesis of findings, and risk of bias were not always considered. This choice was acknowledged as a limitation by the group, but all evidence for the development of the Consensus Statement was searched systematically and rigorously. The triangulation of evidence from multiple sources reinforced our confidence in the final Consensus Statement. Nevertheless, there are limitations to any large consensus building approach to develop similar publicfacing documents. From this experience and others $[1,2$, $65-69,76]$ we recommend that special attention be given to inherent time and resource limitations that invariably constrain timelines and evidence quantity and quality. These realities can create conflict between research standards and knowledge translation needs and demands. In our case, these constraints precluded the lengthy preparation and publication process of systematic reviews (inclusive of review registration and quality assessment in some cases), as each one would have required 6 months or more to have this component achieved before the reviews were discussed among the Expert Panel. It also meant a much smaller window for the stakeholder survey than desirable. Our strengths, on the other hand, included a full series of consensus rounds for the final statement and the process manuscript for all panel members and a large amount of evidence (six reviews, national data, stakeholder survey, discussion time at two occasions among the panel) to make an evidence-based statement.

\section{Conclusions}

In summary, there is broad triangulation support from the published literature, current nationally representative data, the Expert Panel, and the stakeholders consulted to support the Consensus Statement on the Role of the Family in the Physical Activity, Sedentary, and Sleep Behaviours of Children and Youth. This Consensus Statement is intended to facilitate a positive focus on the importance of key practices, policies, and societal actions to promote healthy child and youth growth and development through the integrated 24-h movement behaviours. The release of the Consensus Statement will benefit greatly from the proactive distribution, public relations and media strategy prepared to maximize the reach and impact of the release of the ParticipACTION Report
Card. Through this, it is anticipated that the Consensus Statement will reach relevant government and nongovernment organizations whose work impacts child and youth movement behaviours across Canada and globally. Parents, educators, practitioners, service providers, lawmakers, and government will also be reached through public-facing communications channels (e.g., social media, blog, website) of ParticipACTION and collaborating organizations.

\section{Supplementary information}

Supplementary information accompanies this paper at https://doi.org/10. 1186/s12966-020-00973-0.

Additional file 1 Survey (PDF file of on-line survey). Full survey questions used to solicit assessments and comments from stakeholders on the draft Consensus Statement.

Additional file 2. Table S1 (docx). Inclusion and exclusion criteria for systematic literature searches on family and the physical activity (review $\# 1$ ), sedentary (review \#2), and sleep (review \#3) behaviours of children and youth.

Additional file 3. Review \#1 (docx.). Search Process for Family and Physical Activity Literature Review (review \#1). Themes from the physical activity literature review (review \#1). References for the papers included in the family and physical activity review (review \#1), organized by theme.

Additional file 4. Review \#2 (docx.). Search Process for Family and Sedentary Behaviour Literature Review (review \#2). Themes from the sedentary behaviour literature review (review \#2). References for the papers included in the family and sedentary behaviour review (review \#2), organized by theme.

Additional file 5. Review \#3 (docx.). Search Process for Family and Sleep Behaviour Literature Review (review \#3). Themes from the sleep literature review (review \#3). References for the papers included in the family and sleep review (review \#3), organized by theme.

Additional file 6. Table S2 (doc.). Inclusion and exclusion criteria for systematic literature searches on family systems theory (review \#4), parental correlates (review \#5), and family interventions (review \#6) for movement behaviours of children and youth.

Additional file 7. Review \#4 (docx.). Search Process for the Family Systems in the Context of Child Health Behaviour Change and FamilyBased Interventions Scoping Review (review \#4). References extracted from the Family Systems in the Context of Child Health Behaviour Change Scoping Review (review \#4).

Additional file 8. Review \#5 (docx.). Search Process for the Correlates of Parental Support of Child and Youth Physical Activity, Sedentary Behaviour, and Sleep Systematic Review (review \#5). References Extracted from the Correlates of Parental Support of Child and Youth Physical Activity, Sedentary Behaviour, and Sleep Systematic Review (review \#5).

Additional file 9:. Figure S1 (doc.). Search process of the Review of Reviews on Interventions Involving the Family to Change Child and Youth Physical Activity, Sedentary Behaviour, and Sleep (review \#6).

\section{Acknowledgements}

The authors would like to acknowledge the assistance of Rachel Colley from Statistics Canada for her help with the CHMS custom analyses. We are grateful to Salomé Aubert, Stephanie Carson, Lindsay Crompton, Iryna Demchenko, Tatiana Dimos, Justine Alexis Dryburgh, Savanna Malli, and Emi Vargatoth for their assistance with various aspects of the reviews, referencing, and formatting. We also acknowledge Rebecca Jones and Flip Livingston for the communications input, Hambly \& Wolley for the design and layout of the final Consensus Statement and RAP (Réseau Accès Participation) for its translation into French. 


\section{Authors' contributions}

MST, RER, and LMV conceived and developed the project and with MDG led the manuscript preparation. Reviews \#1-3 were led by MDG. Reviews \#4-6 were led by RER and MP. Supplemental analyses from Statistics Canada were coordinated by MST and LMV and interpreted by MST. The stakeholder survey was coordinated and analyzed by MST, LMV and GF. The conceptual model draft was developed by RER and MP. MST, RER, LMV, MDG, CSB, JPC, GF, IJ, SM, LCM, TLM, KS, JS, NS, KAT, JRT, HW, and FW participated in the Expert Panel meetings. All authors contributed to the development of the conceptual model and reviewed and provided critical feedback on the manuscript. All authors approved the final version of this submission.

\section{Funding}

The Consensus Statement development was supported through funding from the Government of Canada (Sport Canada) and ParticipACTION.

ParticipACTION is a national non-profit organization that helps Canadians sit less and move more. In-kind contributions for Expert Panel participation was provided by each of their respective affiliations. The funding supported travel and expenses for the two Expert Panel meetings, staff salaries for work to complete the six reviews, and costs related to the design, layout, translation, and printing of the Consensus Statement. Sport Canada, ParticipACTION, nor any of the organizations providing in-kind support had editorial privileges on the content of the Consensus Statement.

\section{Availability of data and materials}

Material gathered and collated for the six reviews are included in this manuscript and its supplementary information files. The custom analyses from Statistics Canada in their entirety are available upon reasonable request, pending approval from Statistics Canada. Summaries of the stakeholder survey are provided in the manuscript and detailed results cannot be provided to assure respondent anonymity.

\section{Ethics approval and consent to participate}

The data gathered through the Stakeholder Survey involved "human participants", but only through the feedback survey. Gathering information of this nature does not meet the Canadian Tri-council Policy Statement 2 definition of research (https://ethics.gc.ca/eng/policy-politique_tcps2-eptc2_2018. $\mathrm{html}$ ). The Stakeholder Survey was used to evaluate and gain feedback on the Consensus Statement, which falls under quality assurance/improvement and is exempt from Research Ethics Board review and approval according to Canadian ethics approval guidelines. Stakeholder Survey participants provided passive consent by completing the survey. The survey instructions stated "By completing the survey you provide your consent for us to use your feedback, in aggregated format with other respondents, for reporting purposes. Your responses will be confidential, securely stored and protected, and your anonymity ensured." The complete Stakeholder Survey is available upon request to the corresponding author.

\section{Consent for publication}

All Expert Panel Members are coauthors of this manuscript. Each of them has reviewed the manuscript in its entirety several times and by being coauthors provide consent for their identification as coauthors.

\section{Competing interests}

MST is the Chief Scientific Officer for the ParticipACTION Report Card and the Scientific Chair for the Consensus Statement. He receives no personal compensation for these roles but the Children's Hospital of Eastern Ontario Research Institute receives funding from ParticipACTION for the Healthy Active Living and Obesity Research Group to lead the development of the Report Card and Consensus Statement. LCM received salary support from the BC Children's Hospital Research Institute. LMV is employed by ParticipACTION (serving as the organization's Knowledge Translation Manager) holds a CIHR Fellowship Award. All other authors (RER, MDG, KB, CSB, JPC, GF, IJ, SM, TLM, MP, KS, JS, NS, KAT, JRT, HW, FW) declare they have no competing interests.

\section{Author details}

'Behavioural Medicine Laboratory, Faculty of Education, University of Victoria, PO Box 3010 STN CSC, Victoria, BC V8W 3N4, Canada. ${ }^{2}$ Healthy Active Living and Obesity Research Group, Children's Hospital of Eastern Ontario Research Institute, 401 Smyth Road, Ottawa, ON K1H 8L1, Canada. ${ }^{3}$ ParticipACTION,
Toronto, ON M5S 1M2, Canada. ${ }^{4}$ School of Psychology, University of Ottawa, Ottawa, ON K1N 9A8, Canada. ${ }^{5}$ SickKids Research Institute and the Department of Pediatrics, University of Toronto, Toronto, ON M5G 1X8, Canada. ${ }^{6}$ School of Kinesiology, University of British Columbia, Vancouver, BC V6T 1Z4, Canada. ${ }^{7}$ School of Kinesiology and Health Studies, Queen's University, Kingston, ON K7L 3N6, Canada. ${ }^{8}$ Department of Psychology, Faculty of Arts, University of Calgary, Calgary, AB T2N 1N4, Canada. ${ }^{9} \mathrm{BC}$ Children's Hospital Research Institute / School of Population and Public Health, Faculty of Medicine, University of British Columbia, Vancouver, BC V6H 3N1, Canada. ${ }^{10}$ Faculty of Kinesiology, Sport and Recreation, University of Alberta, Edmonton, Alberta T6G 2H9, Canada. ${ }^{11}$ Families Canada, Ottawa, ON K1S 1V7, Canada. ${ }^{12}$ Faculty of Law \& School of Health Studies, Faculty of Health Sciences, Western University, London, ON N6A 3K7, UK. ${ }^{13}$ The Vanier Institute of the Family, Ottawa, ON K2G 6B1, Canada. ${ }^{14}$ Faculty of Kinesiology and Physical Education, University of Toronto, Toronto, ON M5S 2W6, Canada. ${ }^{15}$ Kids First Parents Association of Canada, Burnaby, BC V5C 2H2, Canada. ${ }^{16}$ Canadian Public Health Association, Ottawa, ON K1G 3Y6, Canada.

Received: 28 February 2020 Accepted: 18 May 2020

Published online: 16 June 2020

\section{References}

1. Tremblay MS, Carson V, Chaput J-P, Connor Gorber S, Dinh T, Duggan M, et al. Canadian 24 hour movement guidelines for children and youth: an integration of physical activity, sedentary behaviour, and sleep. Appl Physiol Nutr Metab. 2016;41(6 Suppl 3):S311-27.

2. Tremblay MS, Chaput JP, Adamo KB, Aubert S, Barnes JD, Choquette L, et al. Canadian 24-hour movement guidelines for the early years ( $0-4$ years): an integration of physical activity, sedentary behaviour, and sleep. BMC Public Heal. 2017;17:874

3. Saunders TJ, Gray CE, Poitras VJ, Chaput JP, Janssen I, Katzmarzyk PT, et al. Combinations of physical activity, sedentary behaviour and sleep: relationships with health indicators in school-aged children and youth. Appl Physiol Nutr Metab. 2016;41(6 Suppl 3):S283-93.

4. Poitras VJ, Gray CE, Borghese MM, Carson V, Chaput JP, Janssen I, et al. Systematic review of the relationships between objectively measured physical activity and health indicators in school-aged children and youth. Appl Physiol Nutr Metab. 2016;41(6 Suppl 3):S197-239.

5. Chaput JP, Gray CE, Poitras VJ, Carson V, Gruber R, Olds T, et al. Systematic review of the relationships between sleep duration and health indicators in school-aged children and youth. Appl Physiol Nutr Metab. 2016;41(6 Suppl 3):S266-82.

6. Carson V, Tremblay MS, Chaput JP, Chastin SFM. Associations between sleep duration, sedentary time, physical activity, and health indicators among Canadian children and youth using compositional analyses. Appl Physiol Nutr Metab. 2016:41(6):S294-302.

7. Carson V, Tremblay MS, Chastin SFM. Cross-sectional associations between sleep duration, sedentary time, physical activity and adiposity indicators among Canadian preschool children using compositional analyses. BMC Public Heal. 2017;17(Suppl 5):848.

8. Poitras VJ, Gray CE, Janssen X, Aubert S, Carson V, Faulkner G, et al. Systematic review of the relationships between sedentary behavior and health indicators in the early years (aged 0-4 years). BMC Public Heal. 2017; 17(868):65-89.

9. Chaput JP, Colley RC, Aubert S, Carson V, Janssen I, Roberts KC, et al. Proportion of preschool-aged children meeting the Canadian 24-hour movement guidelines and associations with adiposity: results from the Canadian health measures survey. BMC Public Heal. 2017;17(Suppl 5):829.

10. Kuzik N, Poitras VJ, Tremblay MS, Lee EY, Hunter S, Carson V. Systematic review of the relationships between combinations of movement behaviors and health indicators in the early years (0 to 4 years). BMC Public Heal. 2017;17(Suppl 5):849.

11. Carson V, Hunter S, Kuzik N, Gray CE, Poitras VJ, Chaput JP, et al. Systematic review of sedentary behaviour and health indicators in school-aged children and youth: an update. Appl Physiol Nutr Metab. 2016;41(6 Suppl 3):S240-65.

12. Carson V, Lee EY, Hewitt L, Jennings C, Hunter S, Kuzik N, et al. Systematic review of the relationships between physical activity and health indicators in the early years (aged 0 to 4 years). BMC Public Heal. 2017;17(854):33-63.

13. Hayes G, Dowd KP, MacDonncha C, Donnelly AE. Tracking of physical activity and sedentary behavior from adolescence to young adulthood: a systematic literature review. J Adolesc Health. 2019;65(4):446-54. 
14. Biddle SJH, Pearson N, Ross GM, Braithwaite R. Tracking of sedentary behaviours of young people: a systematic review. Prev Med. 2010;51(5):345-51.

15. Williamson AA, Mindell JA, Hiscock H, JonQuach J. Sleep problem trajectories and cumulative socio-ecological risks: birth to school-age. J Pediatr. 2019;215:229-37.

16. Rhodes RE, Bredin SSD, Janssen I, Warburton DER, Bauman A. Physical activity: health impact, prevalence, correlates and interventions. Psychol Health. 2017;32:942-75.

17. Malina RM. Physical activity and fitness: pathways from childhood to adulthood. Am J Hum Biol. 2001;13:162-72.

18. World Health Organization. WHO guidelines on physical activity, sedentary behaviour and sleep for children under 5 years of age. Geneva, Switzerland: World Health Organization; 2019.

19. World Health Organization. Global recommendation on physical activity for health. Geneva, Switzerland: World Health Organization; 2010.

20. American Academy of Sleep Medicine. Recommended amount of sleep for pediatric populations: a consensus statement of the American Academy of sleep medicine. J Clin Sleep Med. 2016;12(6):785-6.

21. Hirshkowitz M, Whiton K, Albert SM, Alessi C, Bruni O, DonCarlos L. National Sleep Foundation's updated sleep duration recommendations: final report. Sleep Heal. 2015:1(4):233-43.

22. Reilly JJ, Hughes AR, Janssen $X$, et al. GRADE-ADOLOPMENT process to develop 24-hour movement behavior recommendations and physical activity guidelines for the under 5s in the UK, 2019. J Phys Act Health. 2020; 17(1):101-8

23. Okely AD, Ghersi D, Hesketh KD, Santos R, Loughran SP, Cliff DP, et al. A collaborative approach to adopting/adapting guidelines - the Australian 24hour movement guidelines for the early years (birth to 5 years): an integration of physical activity, sedentary behavior, and sleep. BMC Public Health. 2017:17(Suppl 5):869.

24. American Academy of Pediatrics Council on Communications and Media. Media and young minds. Pediatr. 2016;138(5):e20162591.

25. Australian Department of Health. Australian 24-Hour Movement Guidelines for Children and Young People (5-17 years) - An Integration of Physical Activity, Sedentary Behaviour and Sleep 2019 Available from: https://www1. health.gov.au/internet/main/publishing.nsf/Content/health-24-hours-physact-guidelines.

26. Canadian Pediatric Society. Screen time and young children: promoting health and development in a digital world. Paediatr Child Heal. 2017;22(8):461-8.

27. Institute of Digital Media and Child Development. Children and Screens 2017 Available from: https://www.childrenandscreens.com/.

28. Children's Screen Time Action Network. Campaign for a Commerical-Free Childhood 2020 Available from: https://screentimenetwork.org/.

29. New Zealand Ministry of Health. Sit less, move more, sleep well: active play guidelines for under-fives. Wellington, New Zealand: Ministry of Health; 2017.

30. U.K. Chief Medical Officers' Physical Activity Guidelines. U.K. Government, 2019.

31. U.S. Department of Health and Human Services. Physical Activity Guidelines for Americans. 2nd ed. Washington: US Department of Health and Human Services; 2018

32. Sampasa-Kanyinga $H$, Standage $M$, Tremblay MS. Associations between meeting combinations of 24-hour movement guidelines and health-related quality of life in children from 12 countries. Public Heal. 2017;153:16-24.

33. Lee EY, Spence JC, Tremblay MS, Carson V. Meeting 24-hour movement guidelines for children and youth and associations with psychological wellbeing among south Korean adolescents. Ment Heal Phys Act. 2018;14:66-73.

34. Janssen I, Roberts KC, Thompson W. Is adherence to the Canadian 24-hour movement behaviour guidelines for children and youth associated with improved indicators of physical, mental, and social health? Appl Physiol Nutr Metab. 2017;42(7):725-31.

35. Roman-Viñas B, Chaput JP, Katzmarzyk PT, Fogelholm M, Lambert EV, Maher $\mathrm{C}$, et al. Proportion of children meeting recommendations for 24-hour movement guidelines and associations with adiposity in a 12-country study. Int J Behav Nutr Phys Act. 2016;13:123.

36. Lee EY, Carson V, Jeon JY, Spence JC, Tremblay MS. Levels and correlates of 24-hour movement behaviors among south Koreans: results from the Korea National Health and nutrition examination surveys, 2014 and 2015. J Sport Heal Sci. 2019;8(4):376-85.

37. Walsh JJ, Barnes JD, Cameron JD, et al. Associations between 24- hour movement behaviours and global cognition in US children: a crosssectional observational study. Lancet Child Adolesc Heal. 2018;2(11):783-91.
38. Roberts KC, Yao X, Carson V, Chaput JP, Janssen I, Tremblay MS. Meeting the Canadian 24-hour movement guidelines for children and youth. Heal Reports. 2017;28(10):3-7.

39. Cliff DP, McNeill J, Vella SA, Howard SJ, Santos R, Batterham M, et al. Adherence to 24-hour movement guidelines for the early years and associations with social-cognitive development among Australian preschool children. BMC Public Heal. 2017;17(Suppl 5):857.

40. De Craemer M, McGregor D, Androutsos O, Manios Y, Cardon G. Compliance with 24-h movement behaviour guidelines among Belgian pre-school children: the ToyBox-study. Int J Environ Res Public Heal. 2018;15(10):2171.

41. Manyanga T, Barnes JD, Chaput JP, Katzmarzyk PT, Prista A, Tremblay MS. Prevalence and correlates of adherence to movement guidelines among urban and rural children in Mozambique: a cross-sectional study. Int J Behav Nutr Phys Act. 2019;16:94.

42. Meredith-Jones K, Galland B, Haszard J, Gray A, Sayers R, Hanna M, et al. Do young children consistently meet $24-\mathrm{h}$ sleep and activity guidelines? A longitudinal analysis using actigraphy. Int J Obes. 2019;43:2555-64.

43. Berglind D, Ljung R, Tynelius P, Brooke HL. Cross-sectional and prospective associations of meeting 24-h movement guidelines with overweight and obesity in preschool children. Pediatr Obes. 2018;13(7):442-9.

44. Pearson N, Sherar LB, Hamer M. Prevalence and correlates of meeting sleep, screen-time, and physical activity guidelines among adolescents in the United Kingdom. JAMA Pediatr. 2019;173(10):993-4.

45. Laurson KR, Lee JA, Eisenmann JC. The cumulative impact of physical activity, sleep duration, and television time on adolescent obesity: 2011 youth risk behavior survey. J Phys Act Health. 2015;12(3):355-60.

46. Kracht $\mathrm{CL}$, Webster EK, Staiano AE. Sociodemographic differences in Young children meeting 24-hour movement guidelines. J Phys Act Health. 2019;16: 908-15

47. Chen B, Bernard JY, Padmapriya N, Yao J, Goh C, Tan KH, et al. Sociodemographic and maternal predictors of adherence to 24-hour movement guidelines in Singaporean children. Int J Behav Nutr Phys Act. 2019;16(1):70.

48. Temple VA, Naylor PJ, Rhodes RE, Wharf-higgins SJ. Physical activity of Canadian children in family child care. Appl Physiol Nutr Metab. 2009;34(4): 794-8.

49. Ash T, Agaronov A, Young TL, Aftosmes-tobio A, Davison KK. Family-based childhood obesity prevention interventions: a systematic review and quantitative content analysis. Int J Behav Nutr Phys Act. 2017:14(113):1-12.

50. Dellert JC, Johnson P. Interventions with children and parents to improve physical activity and body mass index: a meta-analysis. Am J Health Promot. 2014;28(4):259-67.

51. Verjans-Janssen SRB, Van De Kolk I, Van Kann DHH, Kremers SPJ, Gerards SMPL. Effectiveness of school-based physical activity and nutrition interventions with direct parental involvement on children's BMI and energy balance-related behaviors - a systematic review. PLoS One. 2018; 13(9):1-24.

52. Rhodes RE, Quinlan A. The family as a context for physical activity promotion. In: Beauchamp MR, Eys MA, editors. Gr Dyn Exerc sport Psychol. 2nd ed. New York: Routledge; 2014. p. 203-21.

53. $\mathrm{Xu} \mathrm{H}$, Wen LM, Rissel C. Associations of parental influences with physical activity and screen time among young children: a systematic review. J Obes. 2015;2015:546925.

54. Pyper $\mathrm{E}$, Harrington D, Manson H. Do parents' support behaviours predict whether or not their children get sufficient sleep? A cross-sectional study. BMC Public Heal. 2017;17:432.

55. Taylor WC, Baranowski T, Sallis JF. Family determinants of childhood physical activity: a social cognitive model. In: Dishman RK, editor. Adv Exerc adherence. Champaign, IL: Human Kinetics; 1994. p. 319-42.

56. Sallis JF, Alcaraz JE, McKenzie TL, Hovell MF, Kolody B, Nader PR. Parental behavior in relation to physical activity and fitness in 9-year-old children. Am J Dis Child. 1992;146(11):1383-8.

57. Beets MW, Cardinal BJ, Alderman BL. Parental social support and the physical activity-related behaviors of youth: a review. Heal Educ Behav. 2010;37(5):621-44

58. Rhodes RE, Lim C. Promoting parent and child physical activity together: elicitation of potential intervention targets and preferences. Heal Educ Behav. SAGE publications Sage CA: Los Angeles. CA. 2018; 45(1):112-23.

59. Trost SG, Sallis JF, Pate RR, Freedson PS, Taylor WC, Dowda M. Evaluating a model of parental influence on youth physical activity. Am J Prev Med. 2003;25(4):277-82 
60. Davison KK, Mâsse LC, Timperio A, Frenn MD, Saunders J, Mendoza JA, et al. Physical activity parenting measurement and research: challenges, explanations, and solutions. Child Obes. 2013;9(Suppl 1):103-9.

61. Trost SG, McDonald S, Cohen A. Measurement of general and specific approaches to physical activity parenting: a systematic review. Child Obes. 2013:9(Suppl 1):S40-50.

62. Cox MJ, Paley B. Family as systems. Annu Rev Psychol. 1997;48:243-67.

63. Minuchin P. Families and individual development: provocations from the field of family therapy. Child Dev. 1985;56(2):289-302.

64. Rothbaum F, Rosen K, Ujiie T, Uchida N. Family systems theory, attachment theory, and culture. Fam Proc. 2002;41(3):328-50.

65. Tremblay MS, Aubert S, Barnes JD, Saunders TJ, Carson V, Latimer-Cheung AE, et al. Sedentary behavior research network (SBRN) - terminology consensus project process and outcome. Int J Behav Nutr Phys Act. 2017;14:75.

66. Tremblay MS, LeBlanc AG, Janssen I, Kho ME, Hicks A, Murumets K, et al. Canadian sedentary behaviour guidelines for children and youth. Appl Physiol Nutr Metab. 2011;36(1):59-64.

67. Tremblay MS, Warburton DER, Janssen I, Paterson DH, Latimer AE, Rhodes RE, et al. New Canadian physical activity guidelines. Appl Physiol Nutr Metab. 2011;36(1):36-46.

68. Tremblay MS, LeBlanc AG, Carson V, Choquette L, Connor Gorber S, Dillman $C$, et al. Canadian physical activity guidelines for the early years (aged 0-4 years). Appl Physiol Nutr Metab. 2012;37:345-56.

69. Tremblay MS, LeBlanc AG, Carson V, Choquette L, Connor Gorber S, Dillman $C$, et al. Canadian sedentary behaviour guidelines for the early years (aged 0-4 years). Appl Physiol Nutr Metab. 2012;37:370-80.

70. Barnes JD, Cameron C, Carson V, Chaput JP, Faulkner GEJ, Janson K, et al. Results from the Canada's 2016 ParticipACTION report card on physical activity for children and youth. J Phys Act Health. 2016;13(2):110-6.

71. Gray C, Larouche R, Barnes J, Colley RC, Cowie Bonne J, Arthur M, et al. Are we driving our kids to unhealthy habits? Results from the active healthy kids Canada 2013 report card on physical activity for children and youth. Int J Environ Res Public Heal. 2014;11:6009-20.

72. Tremblay MS, Barnes JD, Cowie BJ. Impact of the active healthy kids Canada report card: a 10-year analysis. J Phys Act Health. 2014;11(6):3-20.

73. Gray CE, Barnes JD, Cowie Bonne J, Cameron C, Chaput JP, Faulkner G, et al. The 2014 active healthy kids Canada 10th anniversary report card on physical activity for children and youth. J Phys Act Health. 2014;11(S1):26-32.

74. Colley RC, Brownrigg M, Tremblay MS. A model of knowledge translation in health: the active healthy kids Canada report card on physical activity for children and youth. Health Promot Pract. 2012;13(3):320-30.

75. Tremblay MS, Gray CE, Akinroye K, Harrington D, Katzmarzyk PT, Lambert EV, et al. Physical activity of children: a global matrix of grades comparing 15 countries related to the physical activity of children. J Phys Act Health. 2014; 11(Suppl 1):S113-25.

76. Tremblay MS, Gray CE, Babcock S, Barnes JD, Costas Bradstreet C, Carr D, et al. Position statement on active outdoor play. Int J Environ Res Public Heal. 2015;12(6):6475-505.

77. ParticipACTION. The Role of the Family in the Physical Activity, Sedentary and Sleep Behaviours of Children and Youth. The 2020 ParticipACTION Report Card on Physical Activity for Children and Youth. Toronto: ParticipACTION; 2020.

78. Moher D, Liberati A, Tetzlaff J, Altman DG, Grp P. Preferred reporting items for systematic reviews and meta-analyses: the PRISMA statement (reprinted from annals of internal medicine). Phys Ther. 2009;89:873-80.

79. Tricco AC, Lillie E, Zarin W, O'Brien KK, Colquhoun H, Levac D, et al. PRISMA extension for scoping reviews (PRISMA-SCR): checklist and explanation. Ann Intern Med. 2018;169:467-73.

80. Tremblay MS, Wolfson M, Connor GS. Canadian health measures survey: background, rationale and overview. Heal Reports. 2007;18:7-20.

81. Cislak A, Safron M, Pratt M, Gaspar T, Luszczynska A. Family-related predictors of body weight and weight-related behaviours among children and adolescents: a systematic umbrella review. Child Care Health Dev. 2012;38(3):321-31.

82. Cleland V, Timperio A, Salmon J, Hume C, Telford A, Crawford D. A longitudinal study of the family physical activity environment and physical activity among youth. Am J Health Promot. 2011;25(3):159-67.

83. Crawford D, Cleland V, Timperio A, Salmon J, Andrianopoulos N, Roberts R, et al. The longitudinal influence of home and neighbourhood environments on children's body mass index and physical activity over 5 years: the CLAN study. Int J Obes. 2010;34(7):1177-87.
84. Neshteruk CD, Nezami BT, Nino-Tapias G, Davison KK, Ward DS. The influence of fathers on children's physical activity: a review of the literature from 2009 to 2015. Prev Med. 2017;102:12-9.

85. Carlson JA, Sallis JF, Kerr J, Conway TL, Cain K, Frank LD, et al. Built environment characteristics and parent active transportation are associated with active travel to school in youth age 12-15. Br J Sports Med. 2014; 48(22):1634-9.

86. Carson V, Kuhle S, Spence JC, Veugelers PJ. Parents' perception of neighbourhood environment as a determinant of screen time, physical activity and active transport. Can J Public Heal. 2010;101(2):124-7.

87. Cutumisu N, Bélanger-Gravel A, Laferté M, Lagarde F, Lemay JF, Gauvin L. Influence of area deprivation and perceived neighbourhood safety on active transport to school among urban Quebec preadolescents. Can J Public Heal. 2014;105:e376-82.

88. Esteban-Cornejo I, Carlson JA, Conway TL, Cain KL, Saelens BE, Frank LD, et al. Parental and adolescent perceptions of neighborhood safety related to adolescents' physical activity in their neighborhood. Res Q Exerc Sport. 2016;87(2):191-9.

89. Ghekiere A, Deforche B, Carver A, Mertens L, de Geus B, Clarys P, et al. Insights into children's independent mobility for transportation cycling - which socio-ecological factors matter? J Sci Med Sport. 2017;20(3): 267-72.

90. Sterdt E, Liersch S, Walter U. Correlates of physical activity of children and adolescents: a systematic review of reviews. Health Educ J. 2014;73(1):72-89.

91. Mendonça G, Cheng LA, Mélo EN, De Farias Júnior JC. Physical activity and social support in adolescents: a systematic review. Health Educ Res. 2014;29: 822-39.

92. Laird Y, Fawkner S, Kelly P, McNamee L, Niven A. The role of social support on physical activity behaviour in adolescent girls: a systematic review and meta-analysis. Int J Behav Nutr Phys Act. 2016;13:79.

93. Boxberger K, Reimers AK. Parental correlates of outdoor play in boys and girls aged 0 to 12 - a systematic review. Int J Environ Res Public Heal. 2019; 16(2):190.

94. Gordon-Larsen P, McMurray RG, Popkin BM. Determinants of adolescent physical activity and inactivity patterns. Pediatrics. 2000;105(6):e83.

95. Rothman L, Macpherson AK, Ross T, Buliung RN. The decline in active school transportation (AST): a systematic review of the factors related to AST and changes in school transport over time in North America. Prev Med. 2018;111:314-22.

96. La Torre G, Masala D, De Vito E, Langiano E, Capelli G, Ricciardi W. Extracurricular physical activity and socioeconomic status in Italian adolescents. BMC Public Heal. 2006;6:22.

97. Kantomaa MT, Tammelin TH, Näyhä S, Taanila AM. Adolescents' physical activity in relation to family income and parents' education. Prev Med. 2007; 44(5):410-5

98. Bringolf-Isler B, Grize L, Mäder U, Ruch N, Sennhauser FH, Braun-Fahrländer C. Built environment, parents' perception, and children's vigorous outdoor play. Prev Med. 2010;50(5-6):251-6.

99. Heitzler CD, Martin SL, Duke J, Huhman M. Correlates of physical activity in a national sample of children aged 9-13 years. Prev Med. 2006;42(4):254-60.

100. Anderson CB, Hughes SO, Fuemmeler BF. Parent-child attitude congruence on type and intensity of physical activity: testing multiple mediators of sedentary behavior in older children. Health Psychol. 2009;28(4):428-38.

101. Bengoechea EG, Juan FR, Bush PL. Delving into the social ecology of leisure-time physical activity among adolescents from south eastern Spain. J Phys Act Health. 2013;10(8):1136-44.

102. Greenberg RS, Ariza AJ, Binns HJ. Activity and dietary habits of mothers and children: close ties. Clin Pediatr. 2010;49(11):1026-32.

103. Hartson KR, Gance-Cleveland B, Amura CR, Schmiege S. Correlates of physical activity and sedentary behaviors among overweight hispanic school-aged children. J Pediatr Nurs. 2018;40:1-6.

104. Gubbels JS, Kremers SPJ, Stafleu A, Goldbohm RA, de Vries NK, Thijs C. Clustering of energy balance-related behaviors in 5-year-old children: lifestyle patterns and their longitudinal association with weight status development in early childhood. Int J Behav Nutr Phys Act. 2012;9:77.

105. Carson V, Stearns J, Janssen I. The relationship between parental physical activity and screen time behaviors and the behaviors of their young children. Pediatr Exerc Sci. 2015;27(3):390-5.

106. Fuemmeler BF, Anderson CB, Masse LC. Parent-child relationship of directly measured physical activity. Int J Behav Nutr Phys Act. 2011:8:17. 
107. McGuire MT, Hannan PJ, Neumark-Sztainer D, Cossrow NHF, Story M. Parental correlates of physical activity in a racially/ethnically diverse adolescent sample. J Adolesc Health. 2002;30(4):253-61.

108. Morowatisharifabad MA, Karimi M, Ghorbanzadeh F. Watching television by kids: How much and why? J Educ Health Promot. 2015;4:36.

109. Goncalves WSF, Byrne R, Viana MT, Trost SG. Parental influences on screen time and weight status among preschool children from Brazil: a crosssectional study. Int J Behav Nutr Phys Act. 2019;16:27.

110. Carson V, Janssen I. Associations between factors within the home setting and screen time among children aged 0-5 years: a cross-sectional study. BMC Public Heal. 2012;12:539.

111. Hoyos Cillero I, Jago R. Sociodemographic and home environment predictors of screen viewing among Spanish school children. J Public Heal. 2011;33(3):392-402.

112. Garriguet D, Colley R, Bushnik T. Parent-child association in physical activity and sedentary behaviour. Heal Rep. 2017;6(6):3-11.

113. De Decker E, Hesketh K, De Craemer M, Hinkley T, De Bourdeaudhuij I, Salmon J, et al. Parental influences on preschoolers' TV viewing time: mediation analyses on Australian and Belgian data. J Phys Act Health. 2015; 12(9):1272-9.

114. Huang WY, Wong SH, Salmon J. Correlates of physical activity and screenbased behaviors in Chinese children. J Sci Med Sport. 2013;16(6):509-14.

115. Hume C, van der Horst K, Brug J, Salmon J, Oenema A. Understanding the correlates of adolescents' TV viewing: a social ecological approach. Int J Pediatr Obes. 2009:5(2):161-8.

116. Jago R, Sebire SJ, Edwards MJ, Thompson JL. Parental TV viewing, parental self-efficacy, media equipment and TV viewing among preschool children. Eur J Pediatr. 2013;172(11):1543-5.

117. Jago R, Sebire SJ, Lucas PJ, Turner KM, Bentley GF, Goodred JK, et al. Parental modelling, media equipment and screen-viewing among young children: cross-sectional study. BMJ Open. 2013;3:e002593.

118. Jago R, Thompson JL, Sebire SJ, Wood L, Pool L, Zahra J, et al. Crosssectional associations between the screen-time of parents and young children: differences by parent and child gender and day of the week. Int J Behav Nutr Phys Act. 2014;11:54.

119. Drenowatz C, Erkelenz N, Wartha O, Brandstetter S, Steinacker JM, Group UIS. Parental characteristics have a larger effect on children's health behaviour than their body weight. Obes Facts. 2014;7(6):388-98.

120. Hinkley T, Salmon J, Okely AD, Crawford D. The correlates of preschoolers' compliance with screen recommendations exist across multiple domains. Prev Med. 2013;57(3):212-9.

121. Hardy LL, Baur LA, Garnett SP, Crawford D, Campbell KJ, Shrewsbury VA, et al. Family and home correlates of television viewing in 12-13 year old adolescents: the Nepean study. Int J Behav Nutr Phys Act. 2006;3:24.

122. Latomme J, Van Stappen V, Cardon G, Morgan PJ, Lateva M, Chakarova $\mathrm{N}$, et al. The association between children's and parents' co-TV viewing and their total screen time in six European countries: cross-sectional data from the Feel4diabetes-study. Int J Environ Res Public Heal. 2018; 15(11):2599.

123. Davison KK, Francis LA, Birch LL. Links between parents' and girls' television viewing behaviors: a longitudinal examination. J Pediatr. 2005;147(4):436-42.

124. Gorely T, Atkin AJ, Biddle SJ, Marshall SJ. Family circumstance, sedentary behaviour and physical activity in adolescents living in England: project STIL. Int J Behav Nutr Phys Act. 2009;6:33.

125. Vereecken CA, Maes L, De Bacquer D. The influence of parental occupation and the pupils' educational level on lifestyle behaviors among adolescents in Belgium. J Adolesc Health. 2004:34(4):330-8.

126. De Lepeleere S, De Bourdeaudhuij I, Van Stappen V, Huys N, Latomme J, Androutsos $\mathrm{O}$, et al. Parenting practices as a mediator in the association between family socio-economic status and screen-time in primary schoolchildren: a Feel4Diabetes study. Int J Environ Res Public Heal. 2018;15:e2553.

127. Carlson SA, Fulton JE, Lee SM, Foley JT, Heitzler C, Huhman M. Influence of limit-setting and participation in physical activity on youth screen time. Pediatrics. 2010;126:e89-96.

128. Loprinzi PD, Schary DP, Cardinal BJ. Adherence to active play and electronic media guidelines in preschool children: gender and parental education considerations. Matern Child Heal J. 2013;17(1):56-61.

129. MacLeod KE, Gee GC, Crawford P, Wang MC. Neighbourhood environment as a predictor of television watching among girls. J Epidemiol Community Heal. 2010;62:288-92.
130. Patriarca A, Di Giuseppe G, Albano L, Marinelli P, Angelillo IF. Use of television, videogames, and computer among children and adolescents in Italy. BMC Public Heal. 2009;9:139.

131. Poulain T, Vogel M, Sobek C, Hilbert A, Korner A, Kiess W. Associations between socio-economic status and child health: findings of a large German cohort study. Int J Environ Res Public Heal. 2019;16(5):e677.

132. Richter M, Vereecken CA, Boyce W, Maes L, Gabhainn SN, Currie CE. Parental occupation, family affluence and adolescent health behaviour in 28 countries. Int J Public Heal. 2009;54:203-12.

133. Chiu Y-C, Li Y-F, Wu W-C, Chiang T-L. The amount of television that infants and their parents watched influenced children's viewing habits when they got older. Acta Paediatr. 2017;106(6):984-90.

134. Christakis DA, Ebel BE, Rivara FP, Zimmerman FJ. Television, video, and computer game usage in children under 11 years of age. J Pediatr. 2004; 145(5):652-6.

135. Mielke Gl, Brown WJ, Ekelund U, Brage S, Goncalves H, Wehrmeister FC, et al. Socioeconomic position and sedentary behavior in Brazilian adolescents: a life-course approach. Prev Med. 2018;107:29-35.

136. Pinon MF, Huston AC, Wright JC. Family ecology and child characteristics that predict young children's educational television viewing. Child Dev. 1989;60(4):846-56

137. Mushtaq MU, Gull S, Mushtaq K, Shahid U, Shad MA, Akram J. Dietary behaviors, physical activity and sedentary lifestyle associated with overweight and obesity, and their socio-demographic correlates, among Pakistani primary school children. Int J Behav Nutr Phys Act. 2011:8:130.

138. Yalcin SS, TuGrul B, Nacar N, Tuncer M, Yurdakok K. Factors that affect television viewing time in preschool and primary schoolchildren. Pediatr Int. 2002:44(6):622-7.

139. Kesten JM, Sebire SJ, Turner KM, Stewart-Brown S, Bentley G, Jago R. Associations between rule-based parenting practices and child screen viewing: a cross-sectional study. Prev Med Rep. 2015;2:84-9.

140. Saleem M, Hassan A, Mahmood T, Mushtaq S, Bhatti A, Azam M. Factors associated with excessive TV viewing in school children of Wah Cantt. Pakistan Rawal Med J. 2014;39(3):323-6.

141. Goh SN, Teh LH, Tay WR, Anantharaman S, van Dam RM, Tan CS, et al. Sociodemographic, home environment and parental influences on total and device-specific screen viewing in children aged 2 years and below: an observational study. BMJ Open. 2016;6(1):e009113.

142. Sleddens EFC, Gubbels JS, Kremers SPJ, van der Plas E, Thijs C. Bidirectional associations between activity-related parenting practices, and child physical activity, sedentary screen-based behavior and body mass index: a longitudinal analysis. Int J Behav Nutr Phys Act. 2017;14(1):89.

143. Thompson DA, Johnson SL, Vandewater EA, Schmiege SJ, Boles RE, Lev J, et al. Parenting and preschooler TV viewing in low-income Mexican Americans: development of the parenting practices regarding TV viewing (PPRTV) scale. J Dev Behav Pediatr. 2016:37(6):465-74.

144. Verloigne M, Van Lippevelde W, Maes L, Brug J, De Bourdeaudhuij I. Familyand school-based correlates of energy balance-related behaviours in 10-12year-old children: a systematic review within the ENERGY (EuropeaN Energy balance research to prevent excessive weight gain among youth) project. Public Heal Nutr. 2012;15:1380-95.

145. van Zutphen M, Bell AC, Kremer PJ, Swinburn BA. Association between the family environment and television viewing in Australian children. J Paediatr Child Heal. 2007;43(6):458-63.

146. Bounova A, Michalopoulou M, Agelousis N, Kourtessis T, Gourgoulis V. The parental role in adolescent screen related sedentary behavior. Int J Adolesc Med Heal. 2016;30(2):20160031.

147. Cheng JK, Koziol RL, Taveras EM. Parental guidance advised: associations between parental television limits and health behaviors among obese children. Acad Pediatr. 2015;15(2):204-9.

148. De Lepeleere S, De Bourdeaudhuij I, Cardon G, Verloigne M. Do specific parenting practices and related parental self-efficacy associate with physical activity and screen time among primary schoolchildren? A cross-sectional study in Belgium. BMJ Open. 2015;5(9):e007209.

149. Downing KL, Hinkley T, Hesketh KD. Associations of parental rules and socioeconomic position with preschool Children's sedentary behaviour and screen time. J Phys Act Health. 2015;12(4):515-21.

150. Robinson JL, Winiewicz DD, Fuerch JH, Roemmich JN, Epstein LH. Relationship between parental estimate and an objective measure of child television watching. Int J Behav Nutr Phys Act. 2006:3:43. 
151. Bounova A, Michalopoulou M, Agelousis N, Kourtessis T, Gourgoulis V. Home and neighborhood environment predictors of adolescents' screen viewing. J Phys Act Health. 2016;13(12):1310-6.

152. Brindova D, Pavelka J, Sevcikova A, Zezula I, van Dijk JP, Reijneveld SA, et al. How parents can affect excessive spending of time on screen-based activities? BMC Public Heal. 2014;14:1261.

153. Cameron AJ, van Stralen MM, Brug J, Salmon J, Bere E, Chinapaw MJM, et al. Television in the bedroom and increased body weight: potential explanations for their relationship among European schoolchildren. Pediatr Obes. 2013;8:130-41.

154. Cui Z, Hardy LL, Dibley MJ, Bauman A. Temporal trends and recent correlates in sedentary behaviours in Chinese children. Int J Behav Nutr Phys Act. 2011;8:93.

155. de Jong E, Visscher TLS, HiraSing RA, Heymans MW, Seidell JC, Renders CM. Association between TV viewing, computer use and overweight, determinants and competing activities of screen time in 4- to 13-year-old children. Int J Obes. 2013;37:47-53.

156. Johnson L, Chen T-A, Hughes SO, O'Connor TM. The association of parent's outcome expectations for child TV viewing with parenting practices and child TV viewing: an examination using path analysis. Int J Behav Nutr Phys Act. 2015;12:70.

157. Hesketh K, Ball K, Crawford D, Campbell K, Salmon J. Mediators of the relationship between maternal education and children's TV viewing. Am J Prev Med. 2007;33:41-7.

158. Jiang $X-X$, Hardy LL, Ding D, Baur LA, Shi H-J. Recreational screen-time among Chinese adolescents: a cross-sectional study. J Epidemiol. 2014;24:397-403.

159. Saelens BE, Sallis JF, Nader PR, Broyles SL, Berry CC, Taras HL. Home environmental influences on children's television watching from early to middle childhood. J Dev Behav Pediatr. 2002;23:127-32.

160. Billows M, Gradisar M, Dohnt H, Johnston A, McCappin S, Hudson J. Family disorganization, sleep hygiene, and adolescent sleep disturbance. J Clin Child Adolesc Psychol. 2009;5:745-52.

161. Jones $C H D$, Ball $H$. Exploring socioeconomic differences in bedtime behaviours and sleep duration in English preschool children. Infant Child Dev. 2014;23:518-31.

162. Li S, Zhu S, Jin X, Yan C, Wu S, Jiang F, et al. Risk factors associated with short sleep duration among Chinese school-aged children. Sleep Med. 2010; 11(9):907-16.

163. Chen T, Wu Z, Shen Z, Zhang J, Shen X, Li S. Sleep duration in Chinese adolescents: biological, environmental, and behavioral predictors. Sleep Med. 2014;15:1345-53.

164. Buxton OM, Chang AM, Spilsbury JC, Bos T, Emsellem H, Knutson KL. Sleep in the modern family: protective family routines for child and adolescent sleep. Sleep Heal. 2015;1(1):15-27.

165. John B. Sleep-patterns, sleep hygiene behaviors and parental monitoring among Bahrain-based Indian adolescents. J Fam Med Prim Care. 2015;4:232-7.

166. Mindell JA, Williamson AA. Benefits of a bedtime routine in young children: sleep, development, and beyond. Sleep Med Rev. 2018;40:93-108.

167. Tynjälä J, Kannas L, Levälahti E, Välimaa R. Perceived sleep quality and its precursors in adolescents. Health Promot Int. 1999;14:155-66.

168. Bartel KA, Gradisar M, Williamson P. Protective and risk factors for adolescent sleep: a meta-analytic review. Sleep Med Rev. 2015;21:72-85.

169. Mindell JA, Leichman ES, Lee C, Williamson AA, Walters RM. Implementation of a nightly bedtime routine: How quickly do things improve? Infant Behav Dev. 2017:49:220-7.

170. Plancoulaine S, Lioret S, Regnault N, Heude B, Charles MA, Annesi-Maesano I, et al. Gender-specific factors associated with shorter sleep duration at age 3 years. J Sleep Res. 2015;24:610-20

171. Adam EK, Snell EK, Pendry P. Sleep timing and quantity in ecological and family context: a nationally representative time-diary study. J Fam Psychol. 2007;21:4-19.

172. BaHammam A, Bin Saeed A, Al-Faris E, Shaikh S. Sleep duration and its correlates in a sample of Saudi elementary school children. Singap Med J. 2006:47:875

173. Chahal H, Fung C, Kuhle S, Veugelers PJ. Availability and night-time use of electronic entertainment and communication devices are associated with short sleep duration and obesity among Canadian children. Pediatr Obes. 2013;8(1):42-51.

174. Nuutinen T, Ray C, Roos E. Do computer use, TV viewing, and the presence of the media in the bedroom predict school-aged children's sleep habits in a longitudinal study? BMC Public Heal. 2013;13:684.
175. Continente X, Pérez A, Espelt A, López MJ. Media devices, family relationships and sleep patterns among adolescents in an urban area. Sleep Med. 2017;32:28-35.

176. Allen SL, Howlett MD, Coulombe JA, Corkum PV. ABCs of SLEEPING: a review of the evidence behind pediatric sleep practice recommendations. Sleep med. Rev. 2016:29:1-14.

177. Brambilla P, Giussani M, Pasinato A, Venturelli L, Privitera F, Miraglia Del

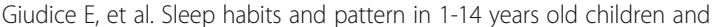
relationship with video devices use and evening and night child activities. Ital J Pediatr. 2017:43:7

178. Touchette É, Petit D, Paquet J, Boivin M, Japel C, Tremblay RE, et al. Factors associated with fragmented sleep at night across early childhood. Arch Pediatr Adolesc Med. 2005;159:242-9.

179. Mindell JA, Sadeh A, Kohyama J, How TH. Parental behaviors and sleep outcomes in infants and toddlers: a cross-cultural comparison. Sleep Med. 2010;11:393-9.

180. Schwichtenberg AJ, Goodlin-Jones B. Causes and correlates of frequent night awakenings in early childhood. Int Rev Neurobiol. 2010;93:177-91.

181. Jiang Y, Chen W, Spruyt K, Sun W, Wang Y, Li S, et al. Bed-sharing and related factors in early adolescents. Sleep Med. 2016;17:75-80.

182. Iwata S, Iwata O, Matsuishi T. Sleep patterns of Japanese preschool children and their parents: implications for co-sleeping. Acta Paediatr. 2013;102:e257-62.

183. Jiang F, Huai YC, Hu WS, Wu H, Wen ZY, Zhao J, et al. An epidemiological study on sleep problems in children aged 1 to 23 months in Shanghai. Zhonghua Yu Fang Yi Xue Za Zhi. 2003;37:435-8.

184. Rea CJ, Smith RL, Taveras EM. Associations of parent health behaviors and parenting practices with sleep duration in overweight and obese children. J Clin Sleep Med. 2016;12:1493-8.

185. Ray C, Kalland M, Lehto R, Roos E. Does parental warmth and responsiveness moderate the associations between parenting practices and children's health-related behaviors? J Nutr Educ Behav. 2013;45:602-10.

186. Spilsbury JC, Storfer-Isser A, Drotar D, Rosen CL, Kirchner HL, Redline S. Effects of the home environment on school-aged children's sleep. Sleep. 2005;28:1419-27.

187. Ray C, Roos E. Family characteristics predicting favourable changes in 10 and 11-year-old children's lifestyle-related health behaviours during an 18month follow-up. Appetite. 2012;58:326-32.

188. Bøe T, Hysing M, Stormark KM, Lundervold AJ, Sivertsen B. Sleep problems as a mediator of the association between parental education levels, perceived family economy and poor mental health in children. J Psychosom Res. 2012;73:430-60.

189. Speirs KE, Liechty JM, Wu CF, Harrison K, Bost K, McBride B, et al. Sleep, but not other daily routines, mediates the association between maternal employment and BMI for preschool children. Sleep Med. 2014;15:1590-3.

190. Schlieber M, Han J. The sleeping patterns of head start children and the influence on developmental outcomes. Child Care Health Dev. 2018:44:462-9.

191. Watanabe E, Lee JS, Kawakubo K. Associations of maternal employment and three-generation families with pre-school children's overweight and obesity in Japan. Int J Obes. 2011;35:945-52.

192. El-Sheikh M, Bagley EJ, Keiley M, Elmore-Staton L, Chen E, Buckhalt JA Economic adversity and children's sleep problems: multiple indicators and moderation of effects. Health Psychol. 2013;32:849-59.

193. Marco CA, Wolfson AR, Sparling M, Azuaje A. Family socioeconomic status and sleep patterns of young adolescents. Behav Sleep Med. 2011;10:70-80

194. Muller D, Paine SJ, Wu L, Signal TL. How long do preschoolers in Aotearoa/ New Zealand sleep? Associations with ethnicity and socioeconomic position. Sleep Heal. 2019;5:452-8.

195. De Jong DM, Cremone A, Kurdziel LBF, Desrochers P, LeBourgeois MK, Sayer A, et al. Maternal depressive symptoms and household income in relation to sleep in early childhood. J Pediatr Psychol. 2016;41:961-70.

196. Acebo C, Sadeh A, Seifer R, Tzischinsky O, Hafer A, Carskadon MA. Sleep/ wake patterns derived from activity monitoring and maternal report for healthy 1- to 5-year-old children. Sleep. 2005;28:1568-77.

197. McDowall PS, Elder DE, Campbell AJ. Relationship between parent knowledge of child sleep, and child sleep practices and problems: a pilot study in a children's hospital cohort. J Paediatr Child Heal. 2017;53:788-93.

198. Peltz JS, Rogge RD, O'Connor TG. Adolescent sleep quality mediates family chaos and adolescent mental health: a daily diary-based study. J Fam Psychol. 2018;33:259-69.

199. Boles RE, Halbower AC, Daniels S, Gunnarsdottir T, Whitesell N, Johnson SL. Family chaos and child functioning in relation to sleep problems among children at risk for obesity. Behav Sleep Med. 2017;15:114-28. 
200. Alfano CA, Smith VC, Reynolds KC, Reddy R, Dougherty LR. The parent-child sleep interactions scale (PSIS) for preschoolers: factor structure and initial psychometric properties. J Clin Sleep Med. 2013;9:1153-60.

201. Koopman-Verhoeff ME, Serdarevic F, Kocevska D, Bodrij FF, Mileva-Seitz VR, Reiss I, et al. Preschool family irregularity and the development of sleep problems in childhood: a longitudinal study. J Child Psychol Psychiatry Allied Discip. 2019;60:857-65.

202. Spilsbury JC, Patel SR, Morris N, Ehayaei A, Intille SS. Household chaos and sleep-disturbing behavior of family members: results of a pilot study of African American early adolescents. Sleep Heal. 2017;3:84-9.

203. El-Sheikh M, Buckhalt JA, Cummings EM, Keller P. Sleep disruptions and emotional insecurity are pathways of risk for children. J Child Psychol Psychiatry Allied Discip. 2007;48(1):88-96.

204. Johnson N, McMahon C. Preschoolers' sleep behaviour: associations with parental hardiness, sleep-related cognitions and bedtime interactions. J Child Psychol Psychiatry Allied Discip. 2008;49:765-73.

205. Keller P, El-Sheikh M. Children's emotional security and sleep: longitudinal relations and directions of effects. J Child Psychol Psychiatry Allied Discip. 2011;52:64-71

206. Bowen M. The use of family theory in clinical practice. Compr Psychiatry. 1966;7(5):345-74.

207. Bowlby J, Ainsworth M, Bretherton I, Ainsworth M. The origins of attachment theory. Dev Psychol. 1992;28(5):759-75.

208. Barnhill LR. Healthy family systems. Fam Coord. 1979;28:94-100.

209. Bronfenbrenner U. Ecology of the family as a context for human development: research perspectives. Dev Psychol. 1986;22:723-42.

210. Davison KK, Jurkowski JM, Lawson HA. Reframing family-centred obesity prevention using the family ecological model. Public Heal Nutr. 2013;16:1861-9.

211. Myoungock J, Whittemore R. The family management style framework for families of children with obesity. J Theory Constr Test. 2015;19:5-14.

212. Kitzman-Ulrich H, Wilson DK, St George MS, Hannah G, Segal M, Fairchild A. The integration of a Family Systems Approach for understanding youth obesity, physical activity, and dietary programs. Clin Child Fam Psychol Rev. 2010;13(3):231-53.

213. Nowicka P, Flodmark CE. Family therapy as a model for treating childhood obesity: useful tools for clinicians. Clin Child Psychol Psychiatry. 2011;16:129-45.

214. Niermann CYN, Gerards SMPL, Kremers SPJ. Conceptualizing family influences on children's energy balance-related behaviors: levels of interacting family environmental subsystems (the LIFES framework). Int J Environ Res Public Heal. 2018;15(12):2714.

215. Nowicka P, Pietrobelli A, Flodmark CE. Low-intensity family therapy intervention is useful in a clinical setting to treat obese and extremely obese children. Int J Pediatr Obes. 2007;2:211-7.

216. Pietrobelli A, Lissau I, Nowicka P, Ho P. Family weight school treatment: 1year results in obese adolescents. Int J Pediatr Obes. 2008;3(3):1-7.

217. Gunn HE, O'Rourke F, Dahl RE, Goldstein TR, Rofey DL, Forbes EE, et al. Young adolescent sleep is associated with parental monitoring. Sleep Heal. 2019;5(1):58-63.

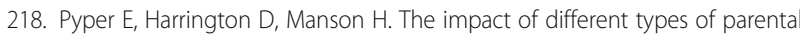
support behaviours on child physical activity, healthy eating, and screen time: a cross-sectional study. BMC Public Heal. 2016;16:568.

219. Rhodes RE, Stearns J, Berry T, Faulkner G, Latimer-Cheung AE, O'Reilly N, et al. Predicting parental support and parental perceptions of child and youth movement behaviors. Psychol Sport Exerc. 2019;41:80-90.

220. Totland TH, Bjelland M, Lien N, Bergh $1 H$, Gebremariam MK, Grydeland M, et al. Adolescents' prospective screen time by gender and parental education, the mediation of parental influences. Int J Behav Nutr Phys Act. 2013;10:1-10.

221. Liszewska N, Scholz U, Radtke T, Horodyska K, Liszewski M, Luszczynska A. Association between children's physical activity and parental practices enhancing children's physical activity: the moderating effects of children's BMI z-score. Front Psychol. 2018:8:1-9.

222. Davison KK, Nishi A, Kranz S, Wyckoff L, May JJ, Earle-Richardson GB, et al. Associations among social capital, parenting for active lifestyles, and youth physical activity in rural families living in upstate New York. Soc Sci Med. 2012;75:1488-96.

223. Zhao J, Gao Z, Settles BH. Determinants of parental perception and support on youth physical activity. Fam Community Heal. 2013;36:77-88.

224. Ice CL, Neal WA, Cottrell L. Parental efficacy and role responsibility for assisting in child's healthful behaviors. Educ Urban Soc. 2014;46:699-715.
225. Huffman LE, Wilson DK, Van Horn ML, Pate RR. Associations between parenting factors, motivation, and physical activity in overweight African American adolescents. Ann Behav Med. 2018;52:93-105.

226. De La Haye K, De Heer HD, Wilkinson AV, Koehly LM. Predictors of parentchild relationships that support physical activity in Mexican-American families. J Behav Med. 2014;37:234-44.

227. Rhodes RE, Spence JC, Berry T, Deshpande S, Faulkner G, Latimer-Cheung A, et al. Understanding action control of parent support behavior for child physical activity. Health Psychol. 2016;35:131-40.

228. Tate EB, Shah A, Jones M, Pentz MA, Liao Y, Dunton G. Toward a better understanding of the link between parent and child physical activity levels: the moderating role of parental encouragement. J Phys Act Health. 2015;12: 1238-44.

229. Cohen J. A power primer. Quant Methods Psychol. 1992;112:155-9.

230. Langer SL, Crain AL, Senso MM, Levy RL, Sherwood NE. Predicting child physical activity and screen time: parental support for physical activity and general parenting styles. J Pediatr Psychol. 2014;39:633-42.

231. Van Sluijs EMF, McMinn AM, Griffin SJ. Effectiveness of interventions to promote physical activity in children and adolescents: systematic review of controlled trials. Br J Sports Med. 2008;42:653-7.

232. Barr-Anderson DJ, Adams-Wynn AW, Disantis KI, Kumanyika S. Familyfocused physical activity, diet and obesity interventions in African-American girls: a systematic review. Obes Rev. 2013;14(1):29-51.

233. Brown HE, Atkin AJ, Panter J, Wong G, Chinapaw M, Van Sluijs EM. Familybased interventions to increase physical activity in children: a systematic review, meta-analysis and realist synthesis. Obes Rev. 2016;17(4):345-60.

234. Golley RK, Hendrie GA, Slater A, Corsini N. Interventions that involve parents to improve children's weight-related nutrition intake and activity patterns what nutrition and activity targets and behaviour change techniques are associated with intervention effectiveness? Obes Rev. 2011;12(2):114-30.

235. Kader M, Sundblom E, Elinder LS. Effectiveness of universal parental support interventions addressing children's dietary habits, physical activity and bodyweight: a systematic review. Prev Med. 2015;77:52-67.

236. Mangunkusumo RT, Brug J, De Koning HJ, Van Der Lei J, Raat H. Schoolbased internet-tailored fruit and vegetable education combined with brief counselling increases children's awareness of intake levels. Public Health Nutr. 2007;10(3):273-9.

237. O'Connor TM, Jago R, Baranowski T. Engaging parents to increase youth physical activity: a systematic review. Am J Prev Med. 2009;37(2):141-9.

238. van Sluijs EMF, Kriemler S, McMinn AM. The effect of community and family interventions on young people's physical activity levels: a review of reviews and updated systematic review. Br J Sports Med. 2011;45(11):914-22.

239. Carson V, Langlois KCR. Associations between parent and child sedentary behaviour and physical activity in early childhood. Heal Rep. 2020;31:3-10

240. United Nations General Assembly. Convention on the Rights of the Child. Sess 44 Resolut 25. 1989.

241. Children First Canada. Canadian Children's Charter. 2020.

242. Stokols D. Establishing and maintaining healthy environments: toward a social ecology of health promotion. Am Psychol. 1992;47(1):6-22.

243. Bronfenbrenner $U$. The ecology of human development: experiments by nature and design. Cambridge, MA: Harvard University Press; 1979.

244. Prochnow T, Delgado H, Patterson M. S., \& Umstattd Meyer MR. social network analysis in child and adolescent physical activity research: a systematic literature review. J Phys Act Health. 2020;17:250-60.

245. Minuchin S. Families and family therapy: Harvard University Press; 1974.

246. Morgan EH, Schoonees A, Sriram U, Faure M, Seguin-Fowler RA. Caregiver involvement in interventions for improving children's dietary intake and physical activity behaviors. Cochrane Database Syst Rev. 2020;5:1.

\section{Publisher's Note}

Springer Nature remains neutral with regard to jurisdictional claims in published maps and institutional affiliations. 